\title{
GRÖSSE, ANLAGEFORMEN, BEFESTIGUNGSARCHITEKTUR UND INNENFLÄCHENBEBAUUNG DER FRÜHEN SLAWISCHEN BURGEN IM SÜDLICHEN HINTERLAND DER OSTSEE
}

\begin{abstract}
Owing to dendrochronological data and archaeological finds, more than 150 strongholds from the southern coastal area of the Baltic Sea between the Lower Elbe and the Lower Vistula, can be identified as the oldest large-scale "fortification horizon" in the North-Western Slavic territories. They developed as early as in the 8th and 9th centuries. Generally, the strongholds are regarded seats of tribal elites. Owing to the rapid development of the local economy and contacts with the neighbouring cultural zones, particularly the Frankish Empire and Scandinavia (ports of trade), the strongholds evolved relatively early in the North-Western Slavic territories. This article focuses on the different aspects of the strongholds' operations: spreading, location, layout, size, construction types, and building structures, in order to present in detail the architectural specifics of the imposing, strongly fortified ramparts. On the basis of archaeological research, the author highlights the erection of the sector fortifications and the joining palisade-like constructions, along with a variety of construction types and materials used. The regional differences in size and the historical-cultural background of these strongholds are also discussed.
\end{abstract}

Keywords: Early Middle Ages, North-Western Slavs, early Slavic strongholds, rampart construction types and building structures.

\section{EINLEITUNG}

Eines der zentralen Forschungsgebiete Władysław Łosińskis (1935-2017) war die früh- und hochmittelalterliche Geschichte Hinterpommerns. Seinen vielfältigen Forschungen, die er in mehreren Monographien und zahlreichen Aufsätzen publizierte, verdanken wir ein umfassendes Bild zur slawisch-mittelalterlichen Besiedlung dieses Raums, wobei seine Studien zum frühmittelalterlichen Siedlungswesen, zur Entwicklung der slawischen Keramik und zum Burgenbau von besonderer Bedeutung sind. Einen Kernraum dieser Forschungen bildete das Einzugsgebiet der unteren Parsęta (Persante), wo bereits in den 50er und 60er Jahren des letzten Jahrhunderts mehrere slawische Burgwälle und deren Siedlungsumfeld untersucht worden sind. Insbesondere die Burgen von Bardy (Bartin), Kędrzyno (Gandelin) Görlitz.

* ORCID: 0000-0001-6190-2567; Kulturhistorisches Museum Görlitz, Neißstraße 29, D-02826 
und Gołańcz Pomorska (Glansee) zählen bis heute zu den am besten untersuchten frühmittelalterlichen Wehranlagen Hinterpommerns; die von W. Losiński (1972) vorgelegten Untersuchungsergebnisse bilden nach wie vor eine zentrale Grundlage für überregionale Untersuchungen zum früh- und hochmittelalterlichen slawischen Burgenbau. Vor diesem Hintergrund möchte sich Verfasser im Folgenden den frühen slawischen Burgen im Hinterland der südlichen Ostseeküste widmen.

Ziel dieses Artikels ist es, verschiedene Aspekte der frühen Burgen - Größe und Anlageform, Wallkonstruktionen, Befestigungsarchitektur und Innenflächenstrukturen - in der Zusammenschau darzustellen, um so zu der durchaus kontroversen Diskussion um die Funktion und den geschichtlichen Hintergrund dieser Burgen beizutragen ${ }^{1}$. Dabei werden über die sogenannten „Feldberger Burgen“2 hinaus alle Burgen betrachtet, die nach derzeitigem Forschungsstand im 8. Jh. und in der ersten Hälfte des 9. Jhs. errichtet wurden (Abb. 1). Aus dem Westen des Arbeitsgebiets sind bislang einige dendrochronologisch datierte Fundplätze bekannt, die anzeigen, dass die Errichtung der ersten Burgen bereits im Verlauf des 8. Jhs. erfolgt sein könnte. Hierzu gehört der um die Mitte des 8. Jhs. datierte Bohlenweg von Sukow; der immense Bauaufwand, der mit der Errichtung des über $2 \mathrm{~km}$ langen Weges verbunden war, spricht eher dafür, dass dieser zu einer Burganlage und nicht zu einer offenen Siedlung führte ${ }^{3}$. Der zum Burgwall im Klempauer Moor führende Bohlenweg wurde nach Dendrodaten 760/61 errichtet (Stark 2003, 88). Besonders frühe Daten aus dem Anfang des 8. Jhs. liegen außerdem für einen Befund aus Wildberg (Temnitz) vor, der aber nicht sicher mit der Burg, sondern ggf. mit einer offenen Siedlung in Zusammenhang steht ${ }^{4}$. Aus Hölzern der Befestigungskonstruktion des Burgwalls von Friedrichsruhe wurden mehrere Dendrodaten gewonnen, die dessen Errichtung in der Zeit um 802 belegen (Messal 2013, 97). Des Weiteren gibt es mehrere Burgen mit Jahrringdaten der ersten Hälfte des 9. Jhs.; zu diesen gehören Alt-Lübeck (817-819), Ilow (ca. 840), Scharstorf (835), Bosau-,,Bischofswarder“ (837) und Oldenburg (9. Jh.) $)^{5}$. Auf dem Burgwall von Lenzersilge in der Prignitz ließen sich zwei Kastenbrunnen dendrochronologisch in die Zeit um 830 und ca. 845 datieren (Biermann/Goßler/Kennecke 2009, 39). Relevante Daten liegen außerdem aus Dorf Mecklenburg und Glienke vor. Dendrodaten aus der Mitte des 10. Jhs. aus der Burgphase C der Mecklenburg lassen darauf schließen, dass die älteste Befestigung bereits in der ersten Hälfte des 9. Jhs.

\footnotetext{
${ }^{1}$ Wichtige Anmerkungen zu diesem Manuskript verdanke ich PD Dr. F. Biermann (Greifswald); Manuskriptabschluss November 2018.

${ }^{2}$ Zur Definition der „Feldberger Burgen“ siehe zuletzt: Biermann 2011; Ruchhöft 2008, 42.

${ }^{3}$ Ruchhöft 2008, 41, 65 f.; Biermann 2011, 152 f.; vgl. hingegen Henning 2002, 139; Dulinicz 2006, 246, 372 f.; zu den Dendrodaten: Henning/Heußner 1991, 265 f.

${ }^{4}$ Zum Befund: Grebe 1970, 150 ff.; zu den Dendrodaten: Dulinicz 2006, 41, 353; vgl. Biermann 2011, 153.

${ }^{5}$ Zu den Daten zusammenfassend: Biermann 2011, 152 ff.; Ruchhöft 2008, 41 [jeweils mit entsprechenden Literaturnachweisen].
} 
errichtet wurde (Ruchhöft 2008, 44 f.; vgl. Dulinicz 2008, 366). Auf dem Niederungsringwall von Glienke wurde die hölzerne Grabenböschungssicherung der dritten Wallphase um 880 errichtet, womit sich der Errichtungszeitraum der ältesten Wehrmauer in die erste Hälfte des 9. Jhs. datieren lässt; die frühe Datierung der Burg wird auch durch die Sukower und Feldberger Keramik belegt, die hier mindestens drei Viertel der auf Burg und Vorburg vertretenen Typen ausmachen (ohne Phasengliederung; Messal 2015, 35, 76 ff., 237). Aus Hinterpommern liegen $\mathrm{m}$. W. bislang nur für eine Burg Dendrodaten vor, die sich eventuell mit einer frühen Bauzeit in Verbindung bringen lassen: Auf dem kleinen Niederungsringwall in Białogard (Belgard) ließen sich einige Bauhölzer der sechsten Wallphase an das Ende des 9. Jhs. datieren, sodass der erste Wallbau bereits im 8. oder frühen 9. Jh., nach dem Ausgräber E. Cnotliwy (2005) sogar noch früher entstanden sein könnte ${ }^{6}$.

Abgesehen von den Dendrodaten und zahlreichen gut datierten Einzelfunden ${ }^{7}$ ist es in vielen Fällen die Gefäßkeramik, über die sich die Burgen zeitlich einordnen lassen. Da diese von zahlreichen Fundplätzen nur in Form weniger Oberflächenfunde oder sehr kleiner Komplexe, die (v. a. in Hinterpommern) bei kleinflächigen Innenflächenuntersuchungen geborgen wurden, vorliegen, sind die Datierungsmöglichkeiten sehr begrenzt. Auschlaggebend für viele frühe Burgendatierungen sind dabei größere Anteile der ältesten slawischen Keramikarten, der Typen Sukow-Dziedzice (ca. spätes 7. Jh. bis Mitte des 9. Jhs.) und Feldberg-Kędrzyno (zweite Hälfte des 8 . Jhs. bis um 900) ${ }^{8}$, sodass zahlreiche Burgen nur ganz allgemein in diesen Zeitraum datiert werden können. Hinzu kommt, dass der Bau einiger Burgen aufgrund fehlender archäologischer Untersuchungen nicht sicher in das Frühmittelalter gesetzt werden kann. Das betrifft insbesondere nicht oder nur mit kleinen Innenflächensondagen untersuchte Burgen, von denen zumeist nur wenige keramische Funde vorliegen, die teils der Lausitzer Kultur, teils dem Frühmittelalter zuzuordnen sind - so z. B. die große zweiteilige Höhenburg von Trzynik (Trienke), wo wenige slawische Gefäßfragmente nur in der Hauptburg gefunden wurden'. Ebenso ist bei den mehrgliedrigen Anlagen oftmals unklar, ob

\footnotetext{
${ }^{6}$ Da bislang kein vollständiges Wallprofil mit einer exakten Zuordnung der datierenden Bauhölzer publiziert wurde, lassen sich diese Ergebnisse allerdings nicht weiter beurteilen; zur Datierung der ältesten Anlage siehe auch: Dulinicz 2006, 309 ff.

${ }^{7}$ So z. B. Haken- und Nietplattensporen der zweiten Hälfte des 8. und der ersten Hälfte des 9. Jhs. vom Burgwall Glienke (Messal 2015, $146 \mathrm{ff}$.).

${ }^{8}$ Siehe zusammenfassend: Kempke 2001, 234 ff.; Ruchhöft 2008, 33 f. Abb. 8.; zum Feldberger Typ: Brather 1996, bes. 143 ff.; zu den hinterpommerschen Typen Gołańcz, Bardy und Kędrzyno: Łosiński 1972, 49 ff. Die ältesten Keramik-Komplexe Hinterpommerns, in denen Keramik des Typs Feldberg-Kędrzyno auftritt, datiert Łosiński $(2008,66)$ spätestens an das Ende des 7. Jhs.; ausschlaggebend ist für den Forscher das Dendrodatum „um 693“ des Sukower Bohlenwegs (Phase IIa), der nach jüngeren Daten aus demselben Bauzusammenhang aber wahrscheinlich erst in der Mitte des 8. Jhs. errichtet wurde (Biermann 2011, 152 ff.; zu den Dendrodaten siehe: Herrmann/Heußner 1991, 265 f.).

${ }_{9}$ Łosiński 1972, 103 f.; Łosiński/Olczak/Siuchniński 1971, 132 f; weitere derartige Anlagen bei Biermann 2011, Anm. 21.
} 
die einzelnen Wallabschnitte zur gleichen Zeit errichtet wurden; so ließ sich auf der zweiteiligen Burg von Reitwein nur in dem östlichen Burgteil Feldberger Keramik finden; von dem westlichen hingegen stammen v. a. mittelslawische Typen (Brather 1996, 215). Insofern bestehen hinsichtlich des Errichtungszeitraums und der Baugeschichte einiger der hier besprochenen Burgen Unwägbarkeiten, die erst infolge weiterer archäologischer Untersuchungen beseitigt werden können.

\section{VERBREITUNG, GRÖSSE UND ANLAGEFORM}

Der Großteil der Burgen liegt in einem etwa 60 bis $120 \mathrm{~km}$ breiten Streifen an der südlichen Ostseeküste, der sich von Ostholstein im Westen bis in das westliche Pommerellen im Osten zieht (Abb. 1). Deren Verbreitungsraum entspricht somit in etwa dem Auftreten der Feldberger Keramik (Brather 1996, 152 ff.). Die südliche Grenze der Hauptverbreitungszone bilden die südlichen Ausläufer der Mecklenburgischen, der Dramburger und der Kaschubischen Seenplatte; wenige Burgen liegen außerdem im nördlichen Brandenburg nördlich von Spree und unterer Havel sowie im nördlichen Großpolen nördlich von Warta (Warthe) und Noteć (Netze). Insbesondere die östliche bzw. südöstliche Grenze des Burgen-Verbreitungsgebiets lässt sich aber bislang nicht sicher bestimmen. Die Burgen verteilen sich in Kernraum verhältnismäßig gleichmäßig; höhere Burgendichten weisen der Raum an der oberen Warnow und am Schweriner See sowie Ostmecklenburg und Vorpommern auf, wo über 30 Burgen in einem breiten Streifen liegen, der vom Saaler Bodden bis zur Uecker reicht. Östlich der Oder sind die Einzugsgebiete von Rega (Rega) und Parsęta durch eine hohe Burgendichte gekennzeichnet; im Osten scheint sich ein weiterer Schwerpunkt an der Słupia (Stolpe) abzuzeichnen. In Ostholstein und Wagrien, in der Prignitz, im nördlichen Oder-Spree-Gebiet sowie im Süden Hinterpommerns treten die Burgen in geringerer Dichte auf. Burgenfreie Räume zeichnen sich in dem Gebiet zwischen Odermündung und Rega sowie im Gebiet westlich der Słupia ab, wobei dieses Bild auch vom Forschungsstand beeinflusst sein könnte.

Bei den Burgen handelt es sich meist um großflächige Anlagen, wobei die Bandbreite allerdings von extrem großen Burgen mit bis zu 10 ha Innenfläche bis $\mathrm{zu}$ sehr kleinen Fortifikationen von lediglich um 0,3 ha Innenfläche reicht (vgl. Abb. $2-7)^{10}$. Trotz dieser Unterschiede kann man aber doch von recht großen Burgen sprechen - zumindest im Vergleich mit den slawischen rund-ovalen Ringburgen des späten 9. und 10. Jhs., die Größen von 40 bis $50 \mathrm{~m}$ Innendurchmesser (ca.

${ }^{10}$ Bei den auf den Abbildungen 2 bis 6 dargestellten Burgengrundrissen handelt es sich um Umzeichnungen, die größtenteils auf älteren Höhenschichtenplänen basieren, die v. a. den einschlägigen Corpora (Herrmann/Donat 1973; 1979a; 1979b; Struve 1981; Łosiński/Olczak/Siuchniński 1971; Olczak/Siuchniński 1966; 1968; 1970; 1985; 1989) entnommen wurden. Insofern sind die Grundrisse als vereinfachte Modelle und die Größen- und Längenangaben als Richtwerte zu betrachten. 
0,13 bis 0,2 ha) nur selten überschreiten. Die sehr großen Burgen mit über 3 ha Innenfläche liegen fast ausschließlich im östlichen Mecklenburg und Vorpommern (Abb. 7). $\mathrm{Zu}$ diesen zählen die Anlagen von Tribsees, Rothemühl, Wildberg bei Altentreptow und Katzow-,,Wrangelsburg“. An diese schließt sich die große Burg von Potzlow im nordöstlichen Brandenburg an. Kleine Burgen mit weniger als 1 h Innenfläche treten hier sehr selten auf (z. B. Schulenberg, Glienke, Jatzke und Fahrenwalde). Westlich dieses Gebiets mit sehr großen Anlagen, im westlichen Mecklenburg, in Ostholstein, in der Prignitz und im Raum an der unteren Havel, sind die Burgen im Durchschnitt etwas kleiner, erreichen mit 1,5 bis 2 ha Innenfläche häufig aber immer noch stattliche Ausmaße. Ausnahmen bilden hier die großen Burgen von Groß Görnow (3,4 ha Innenfläche), der Burgwall von Horst-Wolfshagen (2,06 ha Innenfläche), eventuell auch die Burgwälle von Lochow (2,68 ha Innenfläche; mit befestigter Vorburg) und Hohennauen (vermutlich ca. 3 ha Innenfläche) (vgl. Kennecke 2016, Abb. 3). Auch im Gebiet an der unteren Oder befinden sich mit Szczecin, Waldsieversdorf und Reitwein sehr große Burgen.

Östlich der Oder liegen, soweit bestimmbar, ganz andere Verhältnisse vor. Die einzige Befestigung, die wie mehrere Anlagen Ostmecklenburgs und Vorpommerns über 4 ha Innenfläche aufweist, ist der zweiteilige Burgwall von Trzynik, bei dem es sich aber, wie erwähnt, eventuell um eine spätbronze-/früheisenzeitliche Befestigung mit slawischer Nachnutzung handelt. Bei den größten Burgen, die sicher in das Frühmittelalter datieren, handelt es sich um die Anlagen von Stare Drawsko (Alt Draheim; 1,98 ha Innenfläche) und Bardy (1,5 ha Innenfläche). Abgesehen von sechs weiteren Burgen, die immerhin Innenflächen von 0,5 bis 1 ha aufweisen (Kędrzyno, Lubiechowo [Lübchow], Radacz [Raddatz], Ciecholub [Techlipp], Odargowo [Wudarge], Ostrowiec [Wusterwitz]), und der 1,03 ha großen Anlage von Swobnica (Wildenbruch), weisen sämtliche Burgen Innenflächen von unter 0,5 ha auf. Hinsichtlich der Größenmaße zeigt sich im Durchschnitt also eine deutliche Diskrepanz zwischen den östlich und den westlich der Oder gelegenen Wehrbauten.

Die frühen Burgen weisen stark variierende Grundrisse auf, für die sich kaum eine allgemeingültige Gliederung erstellen lässt. In Abhängigkeit von den örtlichen Gegebenheiten, die bei der Bestimmung der Anlageform der Burgen die ausschlaggebende Rolle spielten, entstanden zahlreiche Anlagen amorpher Gestalt. Dies trifft natürlich insbesondere für zahlreiche große Höhenburgen zu, bei denen natürliche Geländeformen wie Steilhänge, Geländewellen und Taleinschnitte Berücksichtigung fanden (vgl. Abb. 2-4). Unter den Burgen von über 1 ha Innenfläche gibt es nur wenige, die regelmäßige Grundrisse aufweisen; bei diesen handelt es sich v. a. um Niederungsburgen wie z. B. Sukow (etwa rechteckig-oval), Tutow-,,Alte Stadt“ und Oldenburg (rundlich) oder Dorf Mecklenburg (etwa dreieckig). Die kleineren Burgen mit weniger als 1 ha Innenfläche zeigen hingegen häufiger regelmäßige, etwa rundliche (z. B. Lenzen-,,Neuehaus“, Kieve), rundlich-ovale (z. B. Alt-Lübeck, Odargowo, Fahrenwalde) und mehr oder weniger rechteckige Grundrisse (Glienke, Bobolice [Bublitz], Rymań [Roman], Potęgowo [Pottangow]) (vgl. Abb. 5, 6). 


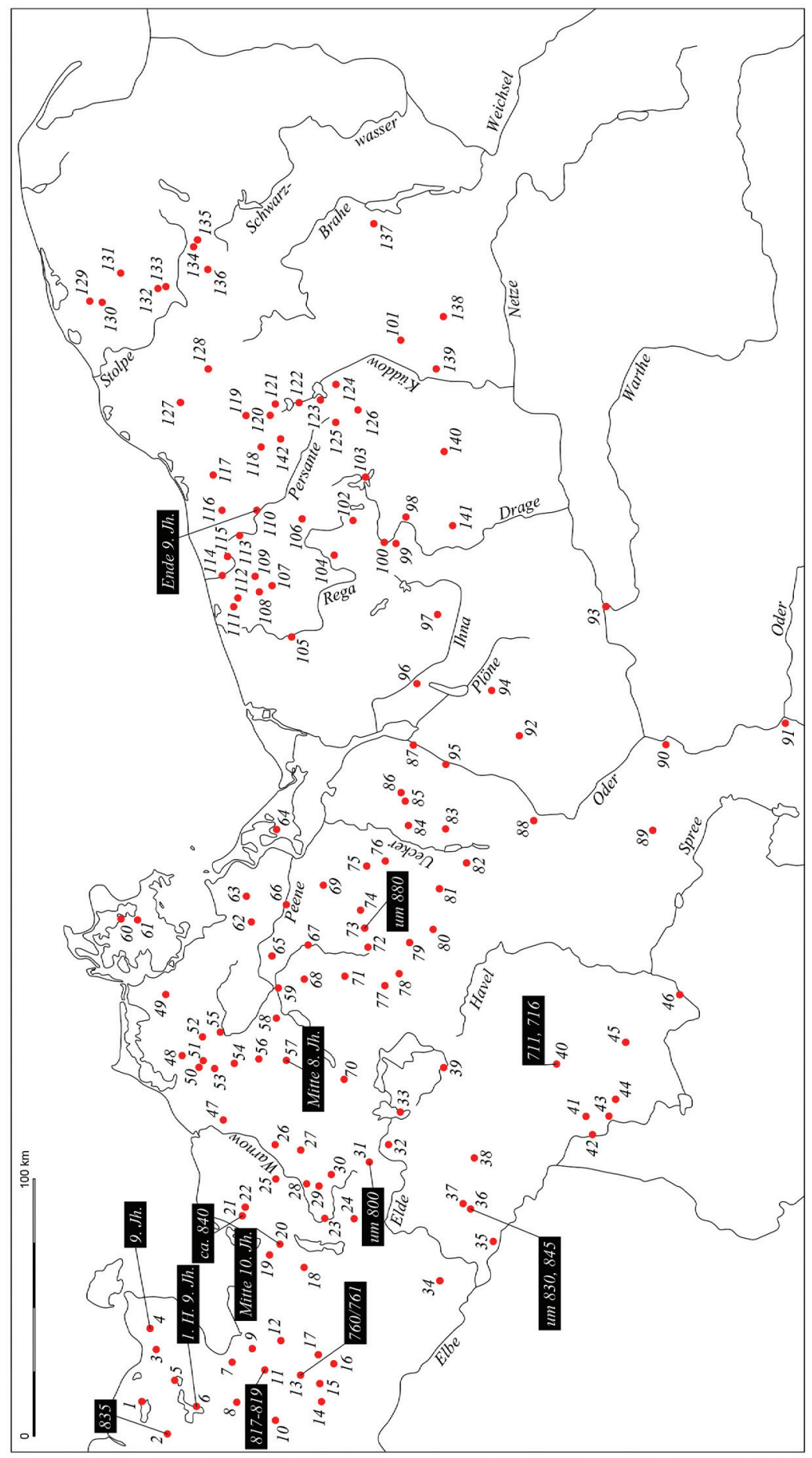




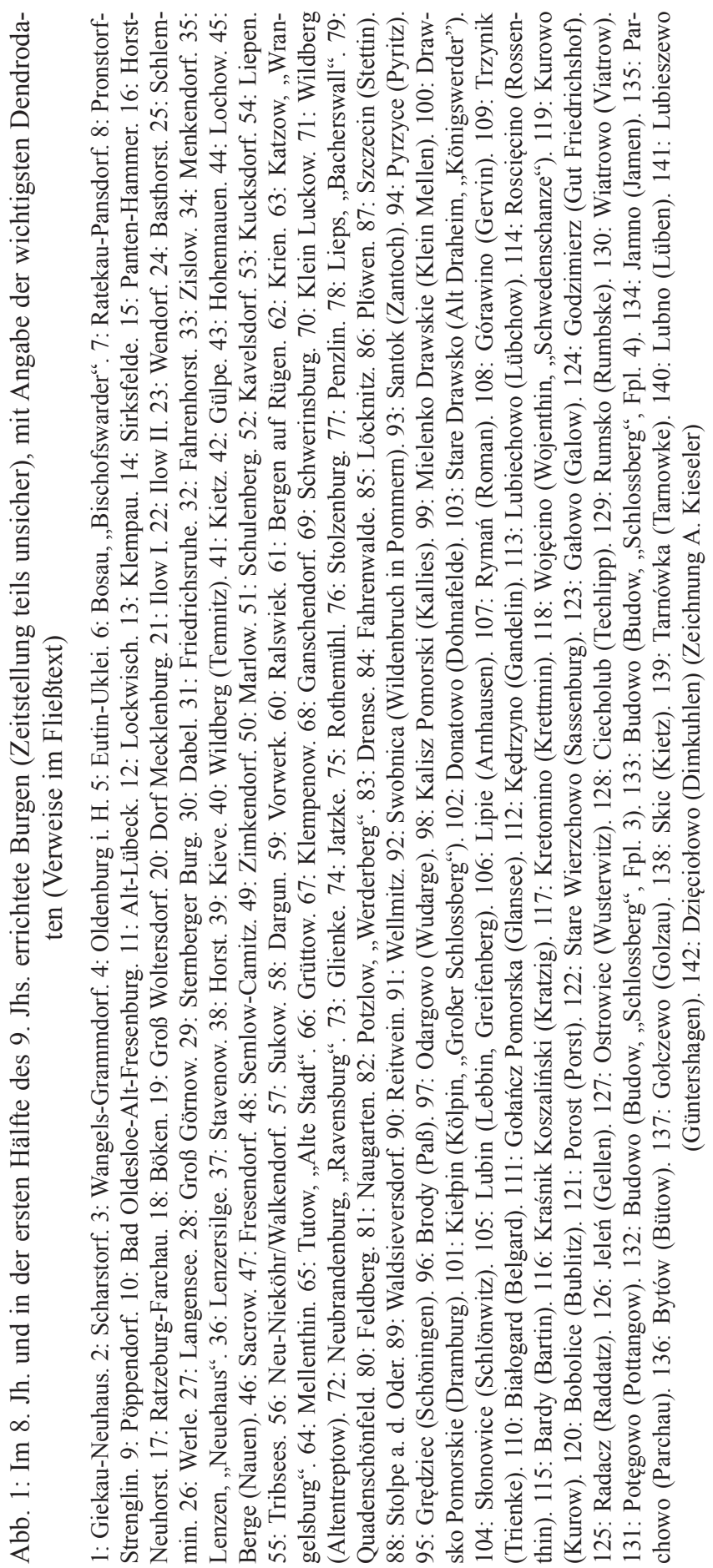


Nur wenige Burgen sind mehrteilig ${ }^{11}$ - fast ausschließlich große Anlagen von über 1 ha Gesamtinnenfläche. $\mathrm{Zu}$ den kleineren mehrteiligen Burgen gehören etwa Ostrowiec, Jatzke, Lubiechowo und Klein Luckow. Die kleinste zweigliedrige Anlage ist mit 0,31 ha Gesamtinnenfläche wohl der Burgwall von Wiatrowo (Viatrow) in Pommerellen. Am häufigsten sind aus Haupt- und Vorburg bestehende Anlagen, selten solche mit drei Elementen, etwa jene von Wildberg (Altentreptow), Neubrandenburg-,,Ravensburg“" und Quadenschönfeld (?); m. W. weist nur eine einzige Anlage vier Burgbereiche auf: der mit vier Abschnittswällen befestigte Burgwall von Dargun. Im Regelfall ist die Hauptburg kleiner als die Vorburg bzw. die Gesamtheit der Vorburgen; eine Ausnahme bildet der Burgwall von Waldsieversdorf mit 1,55 ha großer Vor- und 4,8 ha großer Hauptburg (Abb. 2.4).

\section{WALLKONSTRUKTIONEN}

In Bezug auf die Bauweise der Wallmauern lässt sich mittlerweile auf eine Vielzahl an gut untersuchten Befestigungsanlagen zurückgreifen. Im Großen und Ganzen zeigt sich, dass die frühen Wehranlagen häufig über sehr breite Wehrmauern von 7 bis 9 m Basisbreite verfügten ${ }^{12}$; teilweise erreichen diese aber auch, wie in Dorf Mecklenburg (Donat 1984, 20 Abb. 5 Beil. 2) oder Vorwerk (Herrmann 1969, 193), 12 bis $13 \mathrm{~m}$ Basisbreite. Die Höhen der Wehrmauern sind nur selten sicher anzugeben, doch lassen sich in den meisten Fällen Höhen von 2 bis $5 \mathrm{~m}$ rekonstruieren. Es handelte sich also vorrangig um flach-breite Wälle, denen häufig Wehrgräben als Annäherungshindernisse vorgelagert waren - sehr breite und tiefe Gräben mit wannen- oder muldenförmigem Profil ${ }^{13}$; eine Ausnahme bildet dabei die Oldenburger Befestigung, die zeitweilig von einem Spitzgraben umgeben

${ }^{11} \mathrm{Zu}$ berücksichtigen ist hier, dass die gleichzeitige Errichtung aller Befestigungslinien einer Burg nicht in jedem Fall vorausgesetzt werden kann (vgl. z. B. Schoknecht [1974, 241 ff.] für die ,Ravensburg“ bei Neubrandenburg); in die älteren Großburgen wurden in späteren Zeitabschnitten häufiger kleinere Burgen eingebaut (z. B. Lenzen-,,Neuehaus“, Dargun), sodass letztlich nur eine Untersuchung aller Wallzüge und Innenflächen einer Burg vollständige Klarheit zur Bauabfolge geben kann.

12 Z. B. Stare Drawsko (8 m) (Janocha 1964, Abb. 2), Kędrzyno (9 m), Gołańcz Pomorska (8 m) (Łosiński 1972), Lenzen-,,Neuehaus“ (9 m) (Biermann/Kieseler in Vorbereitung), Liepen (8,6 m) (Schuldt 1962 Abb. 97), Neubrandenburg-,,Ravensburg“ (7-9 m Breite; Kernburg) (Schoknecht 1974, Abb. 3-7), Neu Nieköhr/Walkendorf (8,5 m) (Schuldt 1967, Beil. 2), Sternberger Burg (8 m) (Schuldt 1983, Abb. 4) und Sukow (7-9 m) (Schuldt 1964, Abb. 143); der Wall von Ratekau-Pansdorf dürfte mindestens $10 \mathrm{~m}$ Breite aufgewiesen haben (Struve 1981, 52 Abb. 34).

13 Besonders große Breiten und Tiefen weisen die Gräben von Potzlow (20 m; 4 m) (Biermann/ Henning 2013, 33), Dorf Mecklenburg (15 m; 3,2 m) (Donat 1984, Beil. 2), Szczecin (15 m; $3 \mathrm{~m}$ ) (Wesołowski 1983, 200 Abb. 172; Cnotliwy 1983, 254), Hohennauen (10-15 m; 2,1 m) (Kennecke 2016, 208 Abb. 6), Alt-Lübeck (12,3 m Breite) (Struve 1981, 14), Sternberger Burg (12 m; 1,2 m) (Schuldt 1983, 98), Stare Drawsko (7,8 m; 1,2 m) (Janocha 1964, Abb. 6), Bergen auf Rügen (3-4 m Tiefe) (Herrmann 1998, 169), Lenzen-,Neuehaus“" (11,5 m [teilrekonstruiert]; 1,35 m) (Biermann/ Kieseler in Vorbereitung), Zislow (Vorburg; 10 m; 1,8 m) (Schoknecht 1991, 93), Vorwerk (10 m; 1,4 m) 


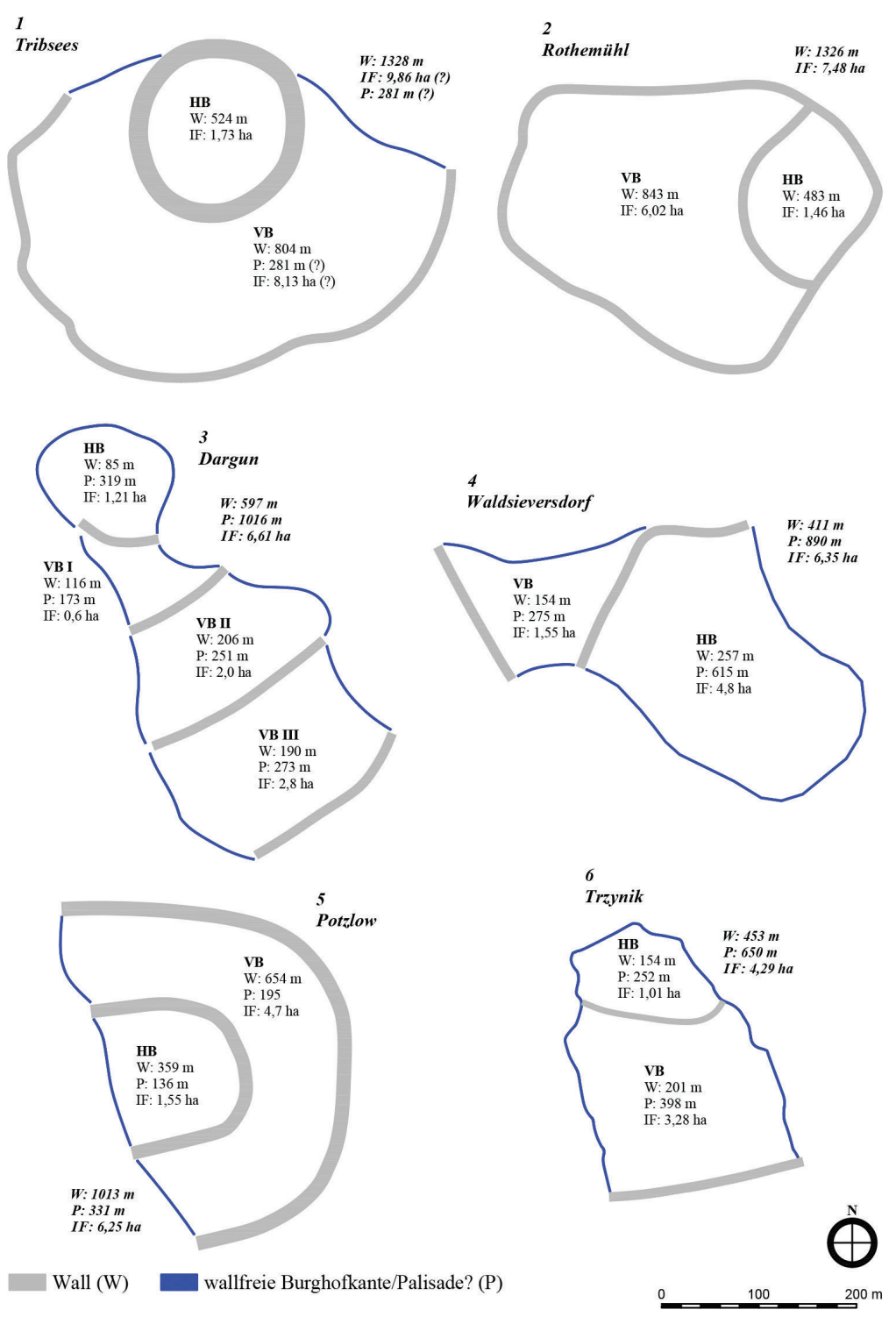

Abb. 2: Schematische Grundrisse mehrgliedriger Burgen von über 4 ha Innenfläche (HB: Hauptburg; VB: Vorburg; IF: Innenfläche) (Entwurf und Zeichnung A. Kieseler)

(Herrmann 1969, Abb. 2), Lubin (8-9 m Breite) (Janowski 2011a, 18), Ratekau-Pansdorf (7,5 m; 1,75 m) (Struve 1981, Abb. 52) und Feldberg (6 m; 2,5 m) (Herrmann 1970, Abb. 4) auf. 
war (Toločko 1991, 117 Abb. 4). Bei den flach-breiten Wällen zeigten sich im Innern der Kernsektionen häufig keine Reste von eingebauten Hölzern. Dies ließe sich insbesondere bei den in Höhenlage errichteten Burgen auf das vollständige Vergehen der Bauhölzer zurückführen, ist aber angesichts der Masse an „holzfreien" Befestigungskernen, die auch bei mehreren Niederungsburgen nachgewiesen wurden (Vorwerk, Lenzen-,,Neuehaus“), nicht in jedem Fall auf Zersetzungsprozesse zurückzuführen. Vielmehr ist davon auszugehen, dass Wälle auch nur aus Erdschüttungen bestehen konnten, die ggf. an den Fronten und auf der Krone mit Holzkonstruktionen und Steinen befestigt wurden ${ }^{14}$. Ein anschauliches Beispiel für ein reines Erdwerk ist der $9 \mathrm{~m}$ breite und etwa 2,5 $\mathrm{m}$ hohe Wall der Niederungsburg von Lenzen-,Neuehaus“, in dem sich keinerlei Holzreste zeigten (Abb. 8). Die aus festem Auelehm bestehende Wehrmauer wurde wahrscheinlich einfach aufgeschüttet und festgestampft, wobei die relativ schrägen Wallfronten keiner zusätzlichen Sicherung bedurften; hölzerne Konstruktionen lassen sich allerdings in Form eines Wehrgangs mit Palisade vermuten (s. u.) (Biermann/Kieseler in Vorbereitung). Auch bei dem flach-breiten Erdwall von Stare Drawsko ist denkbar, dass es sich nur um einen Erdwall mit hölzernem Aufbau in Gestalt einer Palisade handelte. Bei anderen Wällen mit „,holzfreien“ Erdkernen handelte es sich hingegen um Holz-Erde-Konstruktionen, die in verschiedenen Varianten der Schal- und Kastenkonstruktion errichtet wurden. Dies ist v. a. dann anzunehmen, wenn die Wälle nicht aus festem Lehm bestanden, sondern mit sandigem oder humosem Material aufgeschüttet wurden, was zusätzliche Stützkonstruktionen erforderte. Deutlich zeigt sich dies bei der Abschnittsbefestigung vom Burgwall Vorwerk bei Demmin. Deren äußere Wallpackung, die vorwiegend mit beim Ausheben des Grabens gewonnenem Ton und Lehm schichtig aufgeschüttet wurde, blieb - abgesehen von einem Feldsteinbelag - unbefestigt; die innere Wallschüttung hingegen, die sich aus Sand und Humus zusammensetze, wurde an der Rückfront stufenartig mit Holzbalken und Flechtwerk befestigt (Herrmann 1969, 192 ff.).

Die gängigste Bauvariante der frühen Holz-Erde-Mauern dürfte die einfache Schalkonstruktion gewesen sein, bei der der Erdkern auf Vorder- und Rückseite mit mehr oder weniger senkrecht ausgeführten hölzernen Schalwänden bestand. Diese lassen sich im archäologischen Befund häufig nur dann nachweisen, wenn sich Reste der Schalhölzer (zumeist im verbrannten Zustand) erhalten haben. Letzteres ist der Fall bei der Befestigung des Hauptwalls der „Farver Burg“ in Ostholstein. Dort zeigten sich beiderseits der festen, lehmigen Kernschüttung Brandlagen mit teils gut erhaltenen verbrannten Balken, die längs zum Wallverlauf in und unter den Versturzschichten lagen (Abb. 9). Bei diesen handelte es sich zweifelsfrei um die waagerechten Längsbohlen- bzw. Stämme der Wallschalwände, die mit Pfosten oder - wie der Ausgräber vermutete - mit durch bzw. in den Wall führen-

${ }^{14}$ U. a. Gołańcz Pomorska, Glienke, Liepen, Neubrandenburg-,,Ravensburg“, Neu-Nieköhr/Walkendorf, Sternberger Burg, Szczecin und Sukow. 


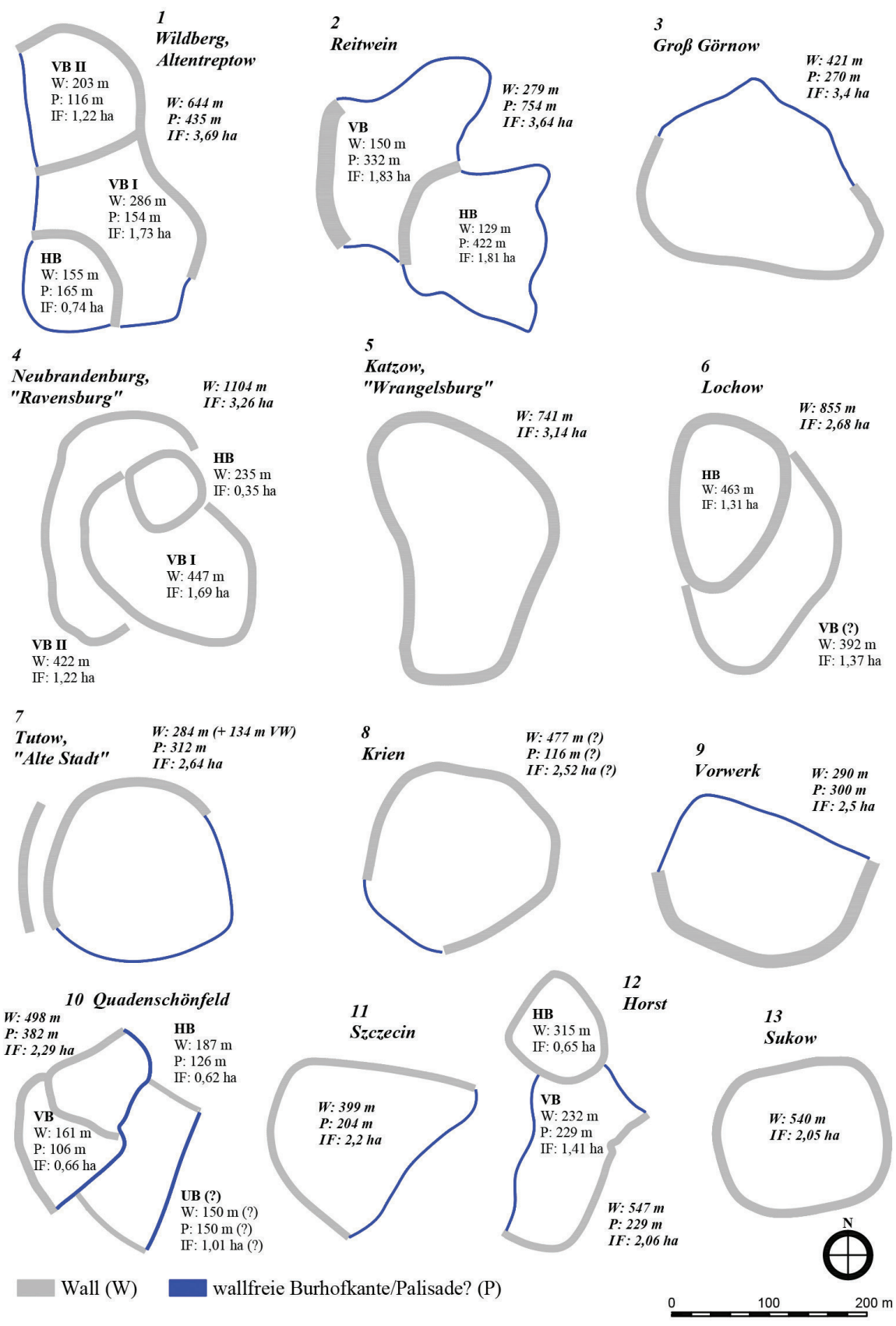

Abb. 3: Schematische Grundrisse ein- bis dreigliedriger Burgen von 2 bis 4 ha Innenfläche (HB: Hauptburg; VB: Vorburg; UB: Unterburg; IF: Innenfläche; VW: Vorwall) (Entwurf und Zeichnung A. Kieseler) 
den Ankerbalken fixiert waren (Struve 1981, 57 f. Abb. 40). Längs zum Befestigungsverlauf liegende Schalwandhölzer oder deren verbannte Reste fanden sich außerdem bei den Befestigungen von Bardy und Kędrzyno (Losiński 1972, 127, 130). Die Frage, ob die Schalhölzer mit Pfosten und/oder Ankerbalken stabilisiert wurden, ist oftmals nicht sicher zu beantworten. Die Wahrscheinlichkeit, dass man in den schmalen Wallschnitten auf die in größeren Abständen an den Wallfüßen eingebrachten Pfosten trifft, ist ebenso gering wie jene, dass sich Ankerbohlen in den beiden Wallprofilen abzeichnen. So ließen sich Anker- oder Stichbalken bei keiner der Schalkonstruktionen sicher nachweisen, und Pfostenlöcher sind in deutlicher Form nur für die Burgen von Kędrzyno (Łosiński 1972, 127 Abb. 51) (Abb. 10), Swobnica (Szafrański 1957, 34 f.; 1960, 44 ff.) und für den „Schlossberg“ von Ralswiek (Herrmann 1998, 149 Beil. 30) belegt. Ein der Schalenbauweise verwandter Konstruktionstyp sind Erdwälle mit Front- und zentralen Stützwänden, wie sie sich z. B. auf der Oldenburg (Toločko 1991, 111 Abb. 4, 5) und in Ralswiek (Herrmann 1998, 149 f. Beil. 32) nachweisen ließen. Regelrechte Kästen mit Längs- und Querwänden im Wallkern ließen sich in der Kernsektion des Burgwalls von Mecklenburg belegen (Donat 1984, 15 ff.) (Abb. 11). Auch auf dem Potzlower „Werderberg“ ließen sich die Reste der verbrannten Wallhölzer der Hauptburg als eine mit Bohlen gefertigte kastenartige Konstruktion ansprechen (Biermann/Henning 2013, 33). Ebenso wurde der Abschnittswall der großen Burg von Hohennauen in Kastenkonstruktion errichtet (Kennecke 2016, 207 f. Abb. 3). Im Vergleich $\mathrm{zu}$ den häufiger nachgewiesenen Schalwand- und Kastenkonstruktionen, die wohl vorrangig mit Flachbohlen errichtet wurden, treten regelrechte Rostkonstruktionen (aus Rundstämmen) nur selten auf ${ }^{15}$.

\section{STEINELEMENTE}

Bei der Errichtung der frühen Burgen wurden häufiger Feldsteine und größere Felsblöcke als Baumaterial verwendet. $\mathrm{Zu}$ den verschiedenen aus Stein ausgeführten Wehrelementen gehören zunächst mehr oder weniger dicht gepackte Steinlagen, die zumeist auf den schrägen Vorderfronten, teils aber auch auf den Innenseiten flächig aufgebracht wurden. Beispiele für gut erhaltene steinerne Wallblenden liegen z. B. von Feldberg (Flachberme) und Radacz (Vorder- und Hinterfront) vor (Abb. 13.a, h). Dichte Steinpackungen sind, zumindest nach oberflächlichen Beobachtungen, auch von den Burgen in Klein Luckow (Bastian 1957, 160), Semlow-Camitz (Berlekamp 1965, 35) und Kucksdorf (Herrmann 1967, 210 f.) bekannt. Die Front-Blenden stellten sicher ein wirksames Mittel gegen Rammangriffe und Steinbeschuss dar, konnten darüber hinaus aber auch den massiv-wehrhaften Ein-

15 So in Feldberg (Herrmann 1970, 36 ff. Abb. 10) (Abb. 12), Bergen auf Rügen (Herrmann 1998, 167 ff. Beil. 32), Kretomino (Skrzypek 2006, 63) und eventuell Białogard (Cnotliwy 1982, 15 ff.). 


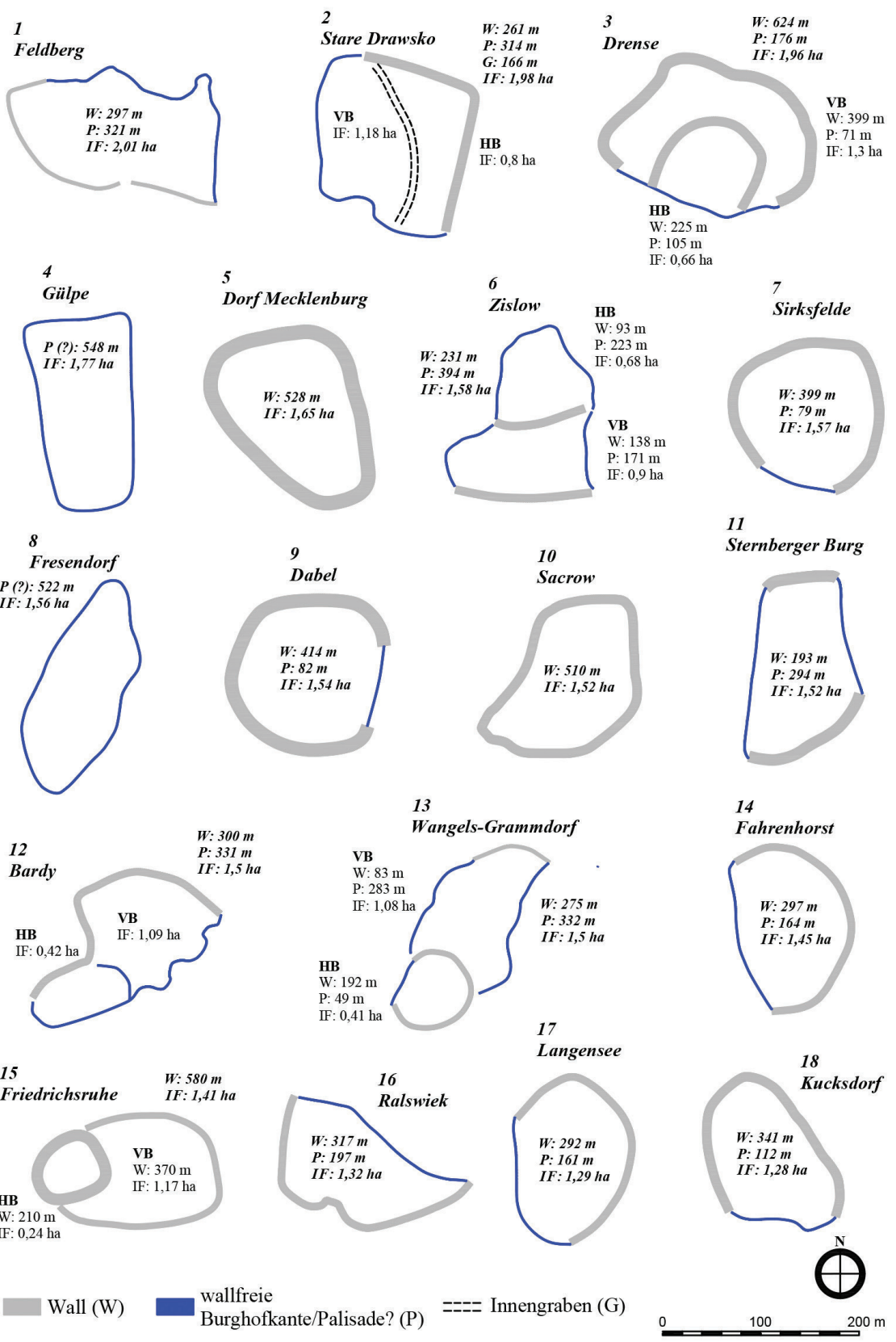

Abb. 4: Schematische Grundrisse ein- bis zweigliedriger Burgen von ca. 1,3 bis 2 ha Innenfläche (HB: Hauptburg; VB: Vorburg; IF: Innenfläche) (Entwurf und Zeichnung A. Kieseler) 
druck der Burg unterstreichen (vgl. Biermann 2015, 42). Bei den dichten Steinlagen, die oberflächlich auf den Wallböschungen zutage treten, kann es sich auch um Ummantelungen der Erdkerne handeln, was aber ohne Walluntersuchungen nicht sicher zu entscheiden ist.

Neben der Errichtung von Blendlagen wurden Steine häufig auch als Füllmaterial im Innern der Wälle verwendet; diese dienten dem Zusammenhalt der Füllschichten, mitunter der Verkeilung von Wallhölzern und der Fixierung von Pfosten. Zuweilen bildeten mehr oder weniger geschlossene Steinlagen auch Wallgrundierungen. So ließ sich auf dem Burgwall von Groß Görnow ein ,in Lehm gesetzte[s] Fundament des Walles aus größeren Blöcken" nachweisen (Schuldt 1985a, 313), und auf der Burg von Kretomino (Krettmin), der abschnittsweise auf einer älteren Siedlungsschicht errichtet wurde, zeigten sich in mehreren Wallbereichen Lagen aus dicht gesetzten kleineren und mittelgroßen Feldsteinen (Skrzypek 2006, 59, 64 Taf. II.B) (Abb. 13.e).

Neben den Blend-, Fundament- und Füllsteinen, die keine konstruktionsbedingte Notwendigkeit darstellen, gibt es mehrere Steinbefunde, die als Teile der eigentlichen Wallkonstruktion zu deuten sind. Zu nennen sind hier in erster Linie Reihen massiver Steine an den Wallfüßen, die als Wallfußstabilisatoren zu deuten sind. Derartige Befunde liegen aus Sukow (Schuldt 1964, 230 Abb. 144), Radacz (Siuchniński 1962, Taf. 6) (Abb. 13.c, f) und vielleicht auch aus Słonowice (Schlönwitz) vor, wo sich mehrere große Steinblöcke von bis zu $80 \mathrm{~cm}$ Durchmesser auf der Außenseite des vermutlich in Bohlen-Kastenkonstruktionen errichteten östlichen Vorwalls fanden (Olczak/Siuchniński 1968, 199 Abb. 155). Auf der Innenseite des in einfacher Schalkonstruktion errichteten Ringwalls von Wangels-Grammdorf (Hauptburg) fanden sich in den Versturzschichten ,einige große, kaum zu bewegende Steinblöcke" (Struve 1981, 57 Abb. 40), die ebenfalls als Fixiersteine der innere Schalwand angesprochen werden können (Abb. 9). Als konstruktive Wallelemente sind aber v. a. die „Steinmauern“ anzusprechen, die bei manchen ohne Holz errichteten Wällen letztlich das Wallgerüst darstellen. $\mathrm{Zu}$ nennen sind hier z. B. die Vorwallbefestigung der „Farver Burg“ in Ostholstein, ein flacher Erdwall aus Sand und Lehm, der an beiden Wallböschungen mit einfachen Steinlagen belegt war (Struve 1981, 58 Abb. 41) (Abb. 14), und die Befestigung von Trzynik, dessen innerer Abschnittswall aus einer Erdschüttung bestand, die beidseitig mit einlagigen Steinschichten befestigt war (Łosiński 1972, 133). Der am massivsten mit Steinen ausgeführte Baubefund dieser Art ist die Wehrmauer des Burgwalls von Liepen im Recknitztal (Schuldt 1962). Der mit Sand und dünnen Lehmpackungen aufgeschüttete Wallkern war an beiden etwa $47^{\circ}$ schrägen Außenseiten mit Feldsteinen bis zu 0,6 $\mathrm{m}$ im Durchmesser in Form tiefer „Trockenmauern“ belegt und erreichte so eine Basisbreite von 8,6 m. Die innere Steinlage hatte eine Stärke von $1,2 \mathrm{~m}$, die äußere wies im Querschnitt die Form eines Dreiecks von $4 \times 4 \times 2,7 \mathrm{~m}$ auf (Abb. 13.g, 15). Der sandige Wallkern wurde hier also von den Wallfüßen bis zur Krone flächig mit tiefen Steinlagen befestigt und so zusammengehalten. Unklar 

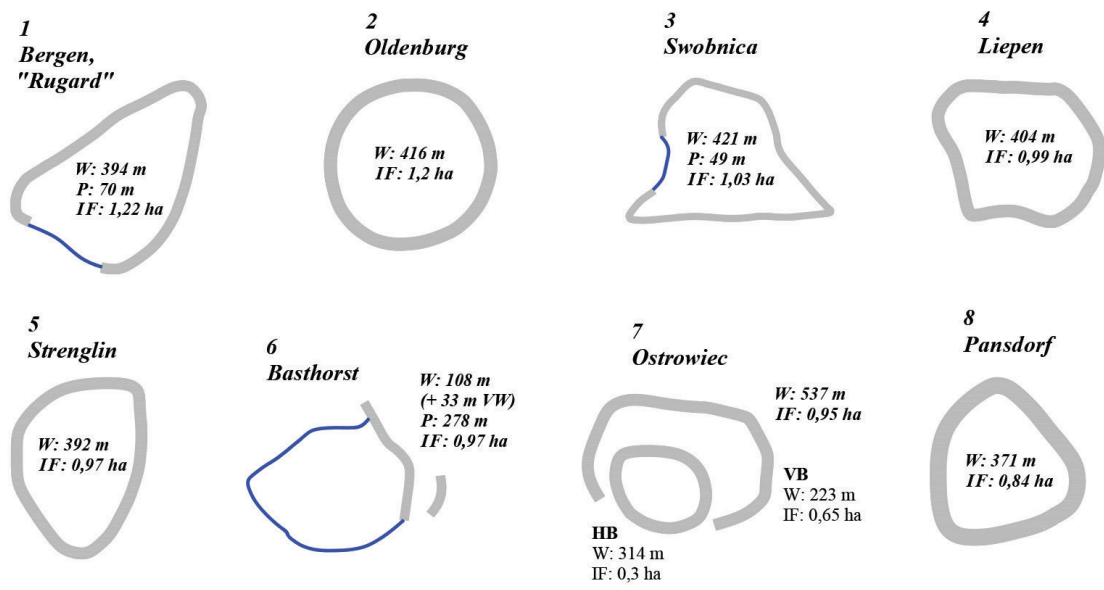

8

W: $371 \mathrm{~m}$
IF: $0,84 \mathrm{ha}$

IF: 0,3 ha
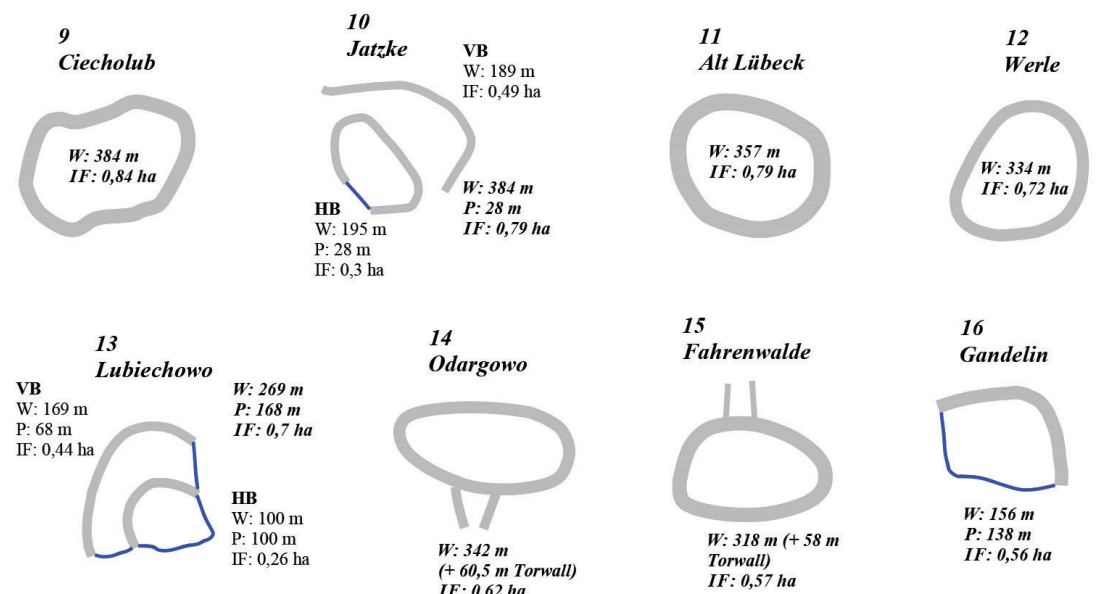

16

Gandelin

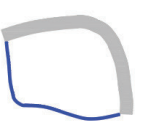

W: $156 \mathrm{~m}$

$P: 138 m$

IF: $0,56 \mathrm{ha}$

17

Bosau, "Bischofswarder"

18
Glienke

19

20
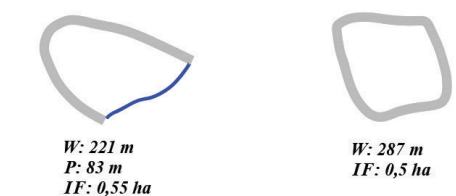

$W: 287 m$
IF: $0,5 \mathrm{ha}$

Lenzen, "Neuehaus"

Alt-Fresenburg
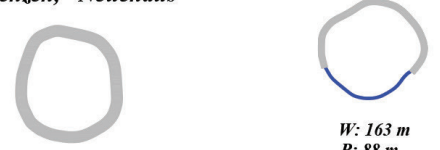

W: $163 \mathrm{~m}$

P: $88 \mathrm{~m}$
IF: $0,46 \mathrm{ha}$

$W: 270 m$
$I F: 0,46 h a$

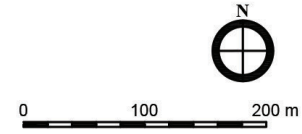

Wall (W) wallfreie Burghofkante/Palisade? (P)

Abb. 5: Schematische Grundrisse ein- bis zweigliedriger Burgen von ca. 0,5 bis 1,3 ha Innenfläche (HB: Hauptburg; VB: Vorburg; IF: Innenfläche) (Entwurf und Zeichnung A. Kieseler) 


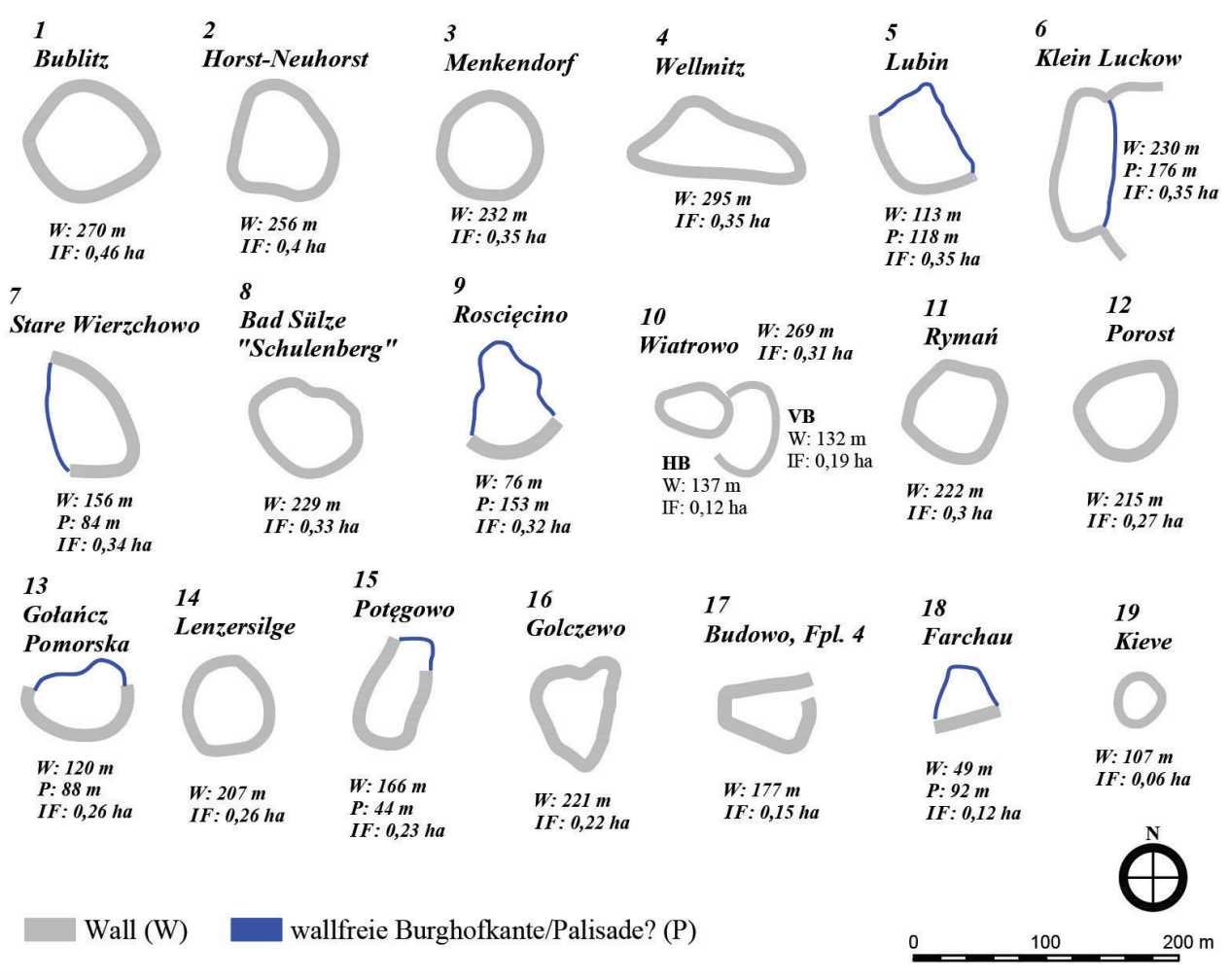

Abb. 6: Schematische Grundrisse ein- bis zweigliedriger Burgen von unter 0,5 ha Innenfläche

(HB: Hauptburg; VB: Vorburg; IF: Innenfläche) (Entwurf und Zeichnung A. Kieseler)

bleibt dabei, ob der auf der Außenseite erfasste Steinkeil von $4 \mathrm{~m}$ Breite im gesamten Wallverlauf errichtet wurde oder ob dieser nur im Bereich des Tores, wo der Wallschnitt angelegt wurde, bestand und somit in Verbindung mit einer Verstärkung der Torwange zu sehen ist; geomagnetische Untersuchungen sprechen für Letzteres (Krug 1971, 40 Abb. 1b). Steinbelegte Tor- und Wallwangen sind darüber hinaus aus Groß Görnow (Schuldt 1985a, 313 ff. Abb. 7) und Gołańcz Pomorska (Łosiński 1972, 127 Abb. 50) bekannt. Nicht mehr sicher zu definierende massive Steinkonstruktionen sind außerdem für die Befestigungen der Oderburgen Reitwein und Neuzelle belegt (Herrmann 1968, 50). Über die genannten bautechnischen Funktionen hinaus ist bei kleinen und mittelgroßen Steinen im Wallbereich, v. a. bei Ballungen im Hinterfrontbereich der Wälle, natürlich auch möglich, dass es sich um zur Burgverteidigung bereitgelegte Schleuder- und Wurfgeschosse handelt (vgl. Toločko 1991, 115). 


\section{WALLAUFBAUTEN}

Zur Gestaltung der Wallkronen und oberen Aufbauten liegen kaum archäologische Zeugnisse vor, da die oberen Wallpartien naturgemäß den stärksten Zerstörungsprozessen unterlagen. Unter wehrtechnischen Gesichtspunkten ist aber grundsätzlich davon auszugehen, dass jede Wallanlage zumindest mit einem Wehrgang und einer Brustwehr ausgestattet war (vgl. z. B. Herrmann 1998, 169; Biermann 2015, 42). Dass diese Elemente aus Holz ausgeführt wurden, liegt auf der Hand, wird aber auch durch die auf zahlreichen Wällen zu beiden Seiten und teils in die Gräben abgeflossenen Brandschichten belegt. Stabile, aus Flachbohlen konstruierte Plattformen waren für das sichere Agieren der Burgverteidiger auf dem Wall unabdingbar. Als Reste solcher Laufgänge lassen sich vielleicht waagerecht verlaufende Brandbänder ansprechen, die sich in den oberen Partien der Wälle von Liepen (Abb. 15) und Dorf Mecklenburg abzeichneten (Schuldt 1962, Abb. 97; Donat 1984, Beil. 2). Die Form der Brustwehren lässt sich auf Grundlage archäologischer Befunde nicht sicher rekonstruieren. Auf einigen Burgen ließen sich auf den Wallkronen noch Reste von Pfostensetzungen ermitteln - so beispielsweise in Weberin-Basthorst (Schuldt 1985a, 325), Radacz (Siuchniński 1964, 157) und Wangels-Grammdorf (Struve 1981, 58 Abb. 41) (Abb. 14). Diese Pfosten dürften zu 1,5 bis $1,7 \mathrm{~m}$ hohen Palisaden, Bohlen- und vielleicht auch Flechtwerkwänden gehört haben, die ggf. über zinnenartige Durchlässe verfügten. Darüber hinaus sind Überdachungen der Laufgänge denkbar, für die zwar keine Befunde vorliegen, die sich aber vielleicht in massiveren Brandversturzschichten zu erkennen geben.

\section{HANGKANTENBEFESTIGUNGEN}

Bei den nur auf den Zugangs- bzw. Angriffsseiten mit Abschnittswällen befestigten Anlagen stellt sich die Frage, ob und in welcher Form man die wallfreien Burghofkanten an den Steilhängen sicherte. $\mathrm{Zu}$ dieser Befestigungsform liegen bislang nur vereinzelt Beobachtungen vor, da bei nahezu allen Ausgrabungen Untersuchungen der Wallbefestigungen, der zumeist stärker genutzten Wallhinterfrontbereiche und der zentralen Hofbereiche im Vordergrund standen.

Auf der großen, im Norden und Osten mit einem ca. 260 mit langen Abschnittswall befestigten Höhenburg auf dem „Königswerder“ bei Stare Drawsko ließen sich an der westlichen Kante des Burghofs, etwa $18 \mathrm{~m}$ über dem Drawsko-See (Dratzig-See) gelegen, mehrere Pfostenstellungen nachweisen, die in einer Nord-Süd-gerichteten Linie dem dortigen Plateaukantenlauf folgten (Janocha 1964, 193 Abb. 7; Olczak/Siuchniński 1970, 155 Abb. 108) (Abb. 16). Die in Reihe gesetzten oder eingetriebenen Pfosten von 8 bis $15 \mathrm{~cm}$ Durchmesser standen in Abständen von 0,1 bis $0,5 \mathrm{~m}$ zueinander, sodass am ehesten davon auszugehen ist, dass diese die Stützen eines leichten Flechtwerkzauns bildeten, wobei nicht auszuschließen ist, 
dass dieser Befund die Reste einer weitestgehend abgetragenen, ursprünglich vollständig geschlossenen Palisade darstellt. Mit diesem Befund liegt aber eher eine einfache Einhegung denn eine stabile Wehrkonstruktion vor, die über der hohen und steilen Seeuferböschung eher dem Schutz der Burgbewohner und des Viehs vor dem Absturz diente.

Massiver stellt sich hingegen die Plateaukantenbefestigung des Burgwalls „Schlossberg“ von Gołańcz Pomorska dar, der auf einer Uferterrasse über dem Tal der Dębosznica (Kreiher Bach) errichtet wurde. An das westliche Ende des halbkreisförmigen Abschnittswalls, der die eher kleine Burg gegen Angriffe von Süden schützte, schlossen sich zwei parallel zueinander verlaufende Pfostenreihen an, die von der steinverstärkten Wallwange in Richtung Nordosten zogen und somit wahrscheinlich die Reste einer Hofkantensicherung auf der Steilhangseite darstellen (Łosiński 1972, 127 Abb. 50c). Die Linie massiver Pfosten von 13 bis $25 \mathrm{~cm}$ Durchmesser wurde auf der dem Burghof zugewandten Seite von einer weiteren Reihe aus dünnen Pfosten (ca. $8 \mathrm{~cm}$ Durchmesser) begleitet (Abb. 17). Ob beide Pfostenlinien eine Konstruktionseinheit bildeten und wie die aufgehende Konstruktion aussah, kann nicht gesagt werden. Die Gleichzeitigkeit beider Pfostenreihen vorausgesetzt, ließe sich eine massive Befestigung in Form der „Zwischen-Pfosten-Konstruktion" erschließen, bei der waagerecht übereinander verlegte Flachbohlen oder Rundhölzer beidseitig mit Pfosten gesichert wurden. Nach den 0,6 m breiten Abständen zwischen den Pfosten könnte man aber, wie im Falle der Konstruktion von Stare Drawsko, auch an Flechtwerkwände denken. Auf dem nur $1 \mathrm{~km}$ südöstlich von Gołańcz Pomorska entfernten „Schlossberg“ von Kędrzyno - ebenfalls eine kleine Burg mit Abschnittswall und offener Burghofkante über dem Tal der Dębosznica - zeigten sich in einem Schnitt am Rande der Burgfläche ebenfalls mehrere Pfostenstellungen, die zu einer burgrandständigen Palisaden- oder Zaunbefestigung gehört haben könnten (Łosiński 1962, 169 f.). Auch im Falle des zweiteiligen Höhenburgwalls von Bardy wurde nur die der Hochfläche zugewandte nordöstliche Flanke mit einem massiven Abschnittswall befestigt. Nach den Ausgrabungsergebnissen auf der kleineren Hauptburg blieb die etwa 270 m lange, dem Flusstal zugewandte südöstliche Seite zunächst unbefestigt und wurde - zumindest im Bereich der „Hauptburg“ - in der ersten Ausbauphase des Hauptwalls mit einem flachen Erdwall versehen, bei dem es sich mit großer Wahrscheinlichkeit um die Anschüttung für eine Palisade handelte; mehrere Pfostengruben und ein länglich-schmaler Grabenbefund, die unter der Aufschüttung entdeckt wurden, wurden vom Ausgräber als Reste von randständigen Gebäuden der ersten Burgphase interpretiert (Łosiński 1972, 149 Abb. 58). Es könnte sich jedoch auch um die Reste der ursprünglichen Palisaden-Hangkantenbefestigung handeln.

Besonders aussagekräftig sind diesbezüglich auch die Ergebnisse der Untersuchungen auf der Sternberger Burg im westlichen Mecklenburg (Schuldt 1983; vgl. 1988, 80). Die 1,5 ha große Anlage war im Norden und Süden mit zwei mächtigen Abschnittswällen, im Osten und Westen hingegen, an den Steilhangseiten zu War- 


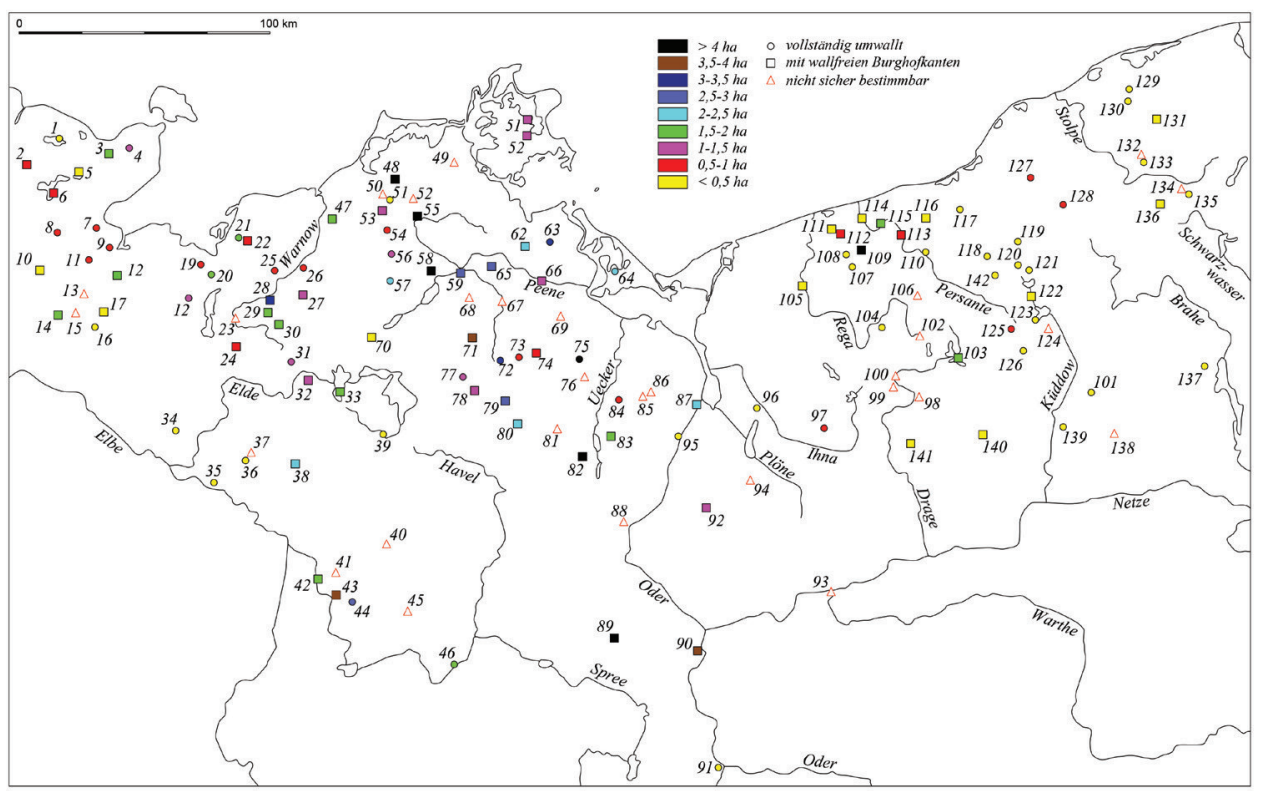

Abb. 7: Gliederung der frühen Burgen nach der Größe der Burginnenflächen unter Angabe der Anlageform der Befestigungsmauer/n (vollständige Umwallung - wallfreie Burghofkante/n); Nummerierung wie bei Abb. 1 (Zeichnung A. Kieseler)

now und Mildenitz, mit zwei flachen Wällen von 173 bzw. $121 \mathrm{~m}$ Länge und etwa 2 bis $3 \mathrm{~m}$ Breite befestigt (Abb. 4.11). Bei diesen handelte es sich um flache Anschüttungen für einreihige hölzerne Befestigungen, die nach den Grabungsbefunden im Ostteil der Burg aus 30 bis $40 \mathrm{~cm}$ dicken, in Abständen von etwa 1,5 m eingegrabenen und teils steinverkeilten Pfosten bestanden. Wie die Flächen zwischen den Pfosten geschlossen waren, lässt sich nicht mehr nachweisen; wahrscheinlich verfügten die Pfosten zu beiden Seiten über senkrechte Nuten, in die waagerecht Bohlen eingeschoben wurden (Abb. 18). Auch in Groß Görnow zeigten sich an der nördlichen, dem Steilhang zugewandten Burghofkante oberflächlich keinerlei Wallreste, doch ließen sich dort in mehreren Schnitten flache Lehmschichten von bis zu 0,75 m Höhe und unter diesen parallel zum Steilhang verlaufende, teils mit Steinen verfüllte Gräbchen nachweisen, die vermutlich palisadenartige Befestigungen darstellen (Schuldt 1985a, 318 ff. Abb. 11, 14). In Klein Luckow werden geringe Wallreste an der dem anschließenden Steilhang zugewandten Ostseite der „Oberburg“ als Basis eines erodierten Wallzugs gedeutet (Bastian 1957, 160 Abb. 138); angesichts des steilen Abfalls zur „Unterburg“ ließen sich diese aber auch als eine Anschüttung für eine Palisade interpretieren.

Diese wenigen Beispiele verdeutlichen, dass wohl bei den meisten Anlagen, deren Burghöfe nur abschnittsweise mit massiven Wällen umwehrt waren, mit mehr oder weniger stabilen Einhegungen oder Befestigungen im Verlauf der offenen 


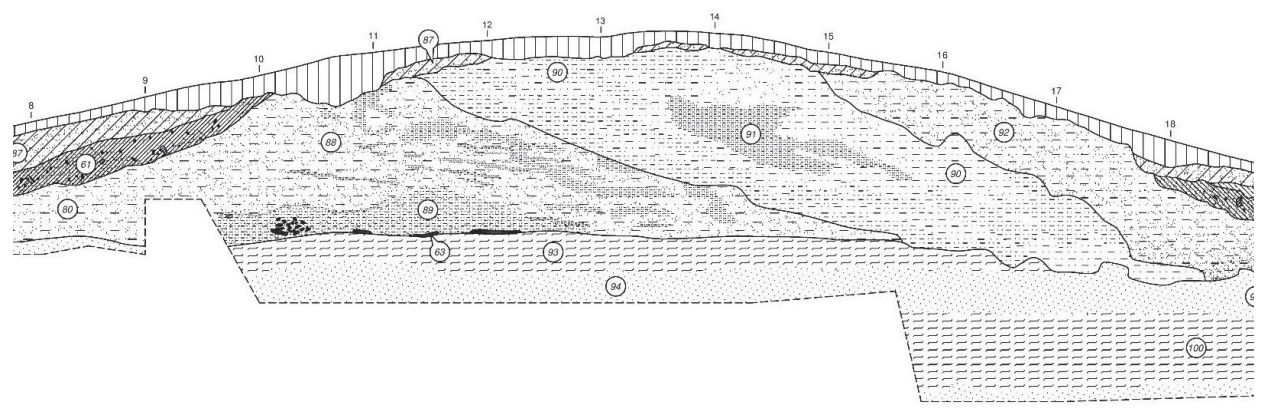

Abb. 8: Lenzen, „Neuehaus“, Lehmwall ohne Holzeinbauten der feldbergzeitlichen Befestigung (Biermann/Kieseler in Vorbereitung)

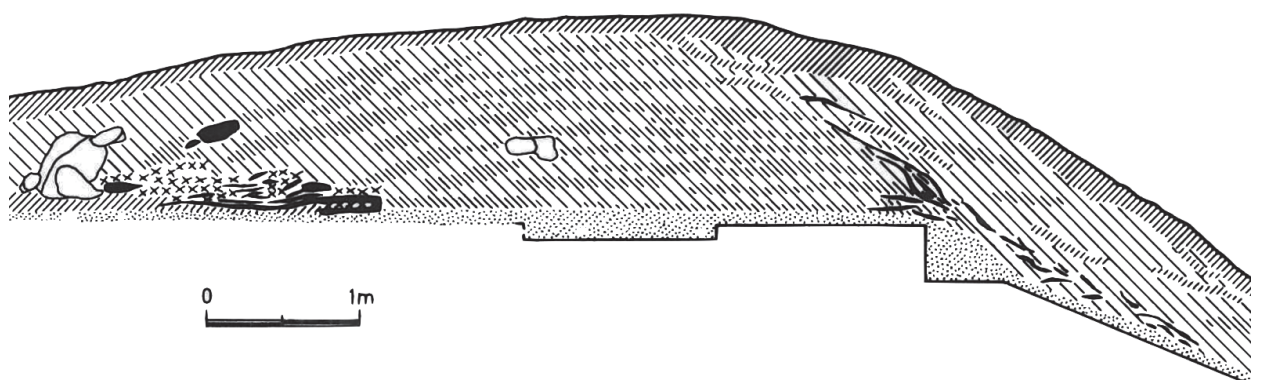

Abb. 9: Wangels-Grammdorf, „Farver Burg“ (Hauptburg), Erdwall mit verbrannten Schalwänden und Steinsicherung am Innenfuß (?) (Struve 1981, Abb. 40)

Burgplateaukanten zu rechnen ist. Offenbar wurden diese Konstruktionen je nach Böschungsgrad und somit Verteidigungswert der Steilhänge mehr oder weniger stabil und wehrhaft ausgeführt. Bei Burgen mit hohen und steilen Hängen, die wie in Feldberg oder Stare Drawsko direkt an ein Gewässer grenzten, konnte man auf die Errichtung massiver Befestigungen verzichten; verliefen die Böschungen, wie beim Großteil der Anlagen, flacher, mussten stabilere Wehrkonstruktionen errichtet werden.

Den Burgengrundrissen zufolge dürften die Plateaukantenbefestigungen in Gestalt von Palisaden, pfostengestützten Bohlenwänden und Flechtwerkzäunen jedenfalls einen bedeutenden Anteil an den Befestigungswerken der frühen Burgen gehabt haben. So weisen etwa 50\% dieser Anlagen in der einen oder anderen Form Burghofkanten auf, die nicht mit Wällen und ggf. mit Palisaden oder ähnlichen Konstruktionen befestigt wurden. Je nach Geländesituation nehmen die wallfreien Abschnitte bei den eingliedrigen Burgen häufig nur 15\% bis 50\% der Burghofkan- 


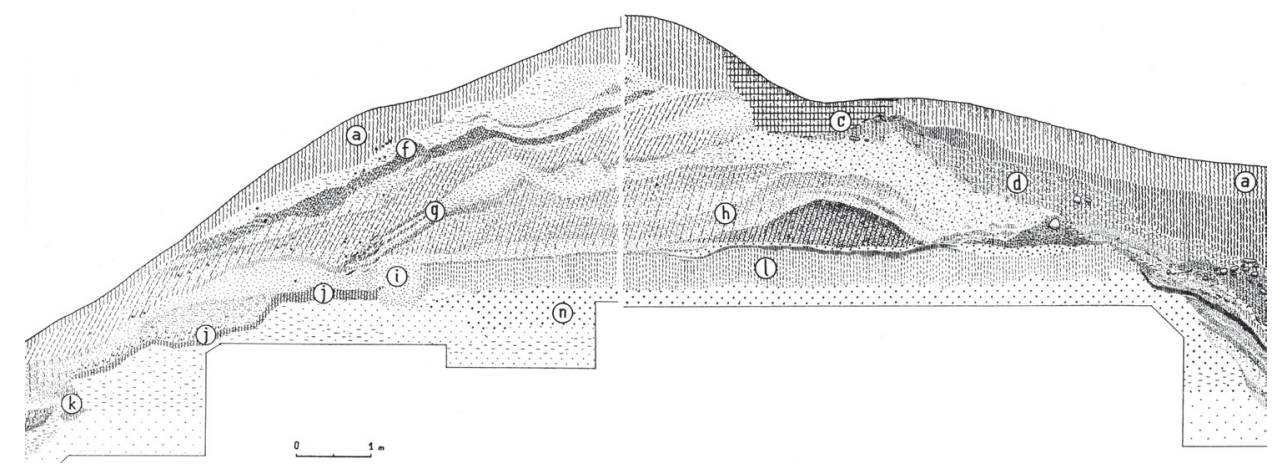

Abb. 10: Kędrzyno, Wall mit Erdkern und Pfostenspur (i) am äußeren Wallfuß (Łosiński 1972, Abb. 51)

ten ein ${ }^{16}$, liegen teilweise aber auch über $50 \%{ }^{17}$. Ähnliche Verhältnisse lassen sich außerdem für eine Reihe von mehrgliedrigen Befestigungen erkennen (vgl. Abb. 2-6) ${ }^{18}$. Nicht auszuschließen ist, dass man bei einigen Burgen vollständig auf die Errichtung von Wällen verzichtete. In entsprechender Lage, z. B. auf einem Hochplateau mit steilen Böschungen, boten Palisaden bzw. flache Palisadenwälle ausreichend Schutz und gewährleisteten die Verteidigungsfähigkeit der Burg ${ }^{19}$.

\section{INNENFLÄCHENBEBAUUNG}

Hinsichtlich der Innenflächenbebauung der frühen Burgen liegen bislang nur begrenzte Grabungsergebnisse vor. Im Wesentlichen wurden die Burgflächen im direkten Hinterfrontbereich mit einzelnen Sondagen oder kombinierten Wall-Innenflächen-Schnitten untersucht. Großflächige Untersuchungen der zentralen Burgbe-

${ }^{16}$ So z. B. in Bardy (ohne Befestigung zwischen Haupt- und Vorburg) (48\%), Kędrzyno (47\%), Gołańcz Pomorska (42\%), Groß Görnow (39\%), Langensee (36\%), Stare Wierzchowo (Sassenburg) und Alt-Fresenburg (jeweils 35\%), Szczecin (ca. 34\%), Bosau-,Bischofswarder“ (27\%), Kucksdorf (25\%), Krien (20\%), Sirksfelde (17\%) und Dabel (16\%).

17 So z. B. in Basthorst (72\%; ohne Vorwall), Roscięcino (Rossenthin) (67\%), Sternberger Burg $(60 \%)$, Stare Drawsko (55\%), Feldberg und Tutow (ohne Vorwall) (jeweils 52\%), Lubin (Lebbin) und Vorwerk (jeweils $51 \%$ ).

${ }^{18}$ Etwa in Reitwein (73\%), Waldsieversdorf (68\%), Dargun (63\%), Zislow (63\%), Trzynik (59\%), Wangels-Grammdorf (55\%), Quadenschönfeld (43\%), Wildberg (Altentreptow) (40\%), Lubiechowo (38\%), Horst (30\%), Potzlow (25\%) und Tribsees (18\%).

$19 \mathrm{Zu}$ diesen Anlagen sind vielleicht der Fresendorfer „Schlossberg“ (Herrmann/Donat 1973, 5/7), die Burg von Gülpe (HerrmannDonat 1979b, 78/28) und der „Schlossberg“ bei Bytów (Bütow) (Olczak/Siuchniński 1989, 28 ff.) zu zählen. 


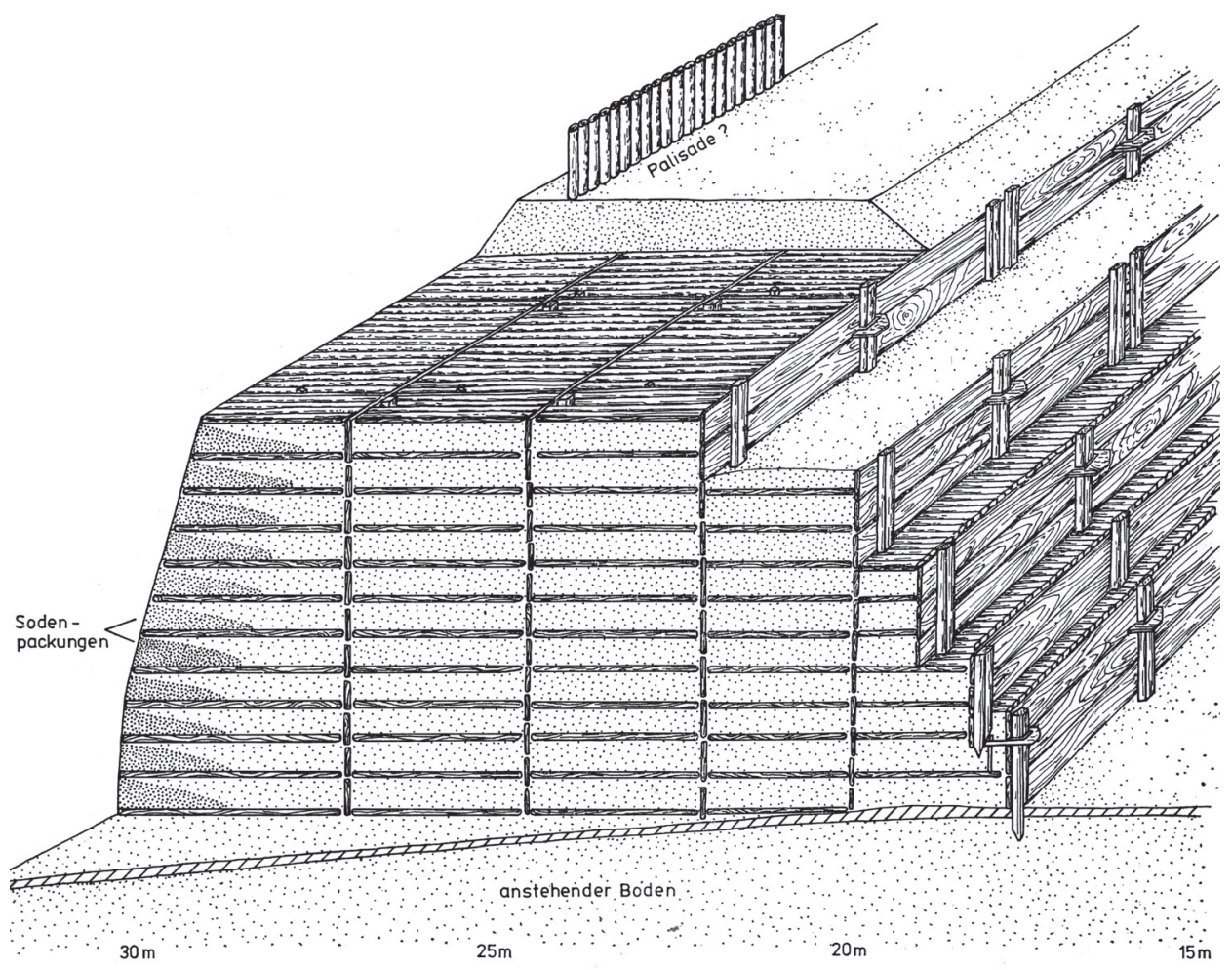

Abb.11: Dorf Mecklenburg, Rekonstruktion des Kastenwalls der ersten Phase (Donat 1984, Abb. 5)

reiche sind hingegen selten; nur die hinterpommerschen Burgen wurden mehrfach mit kleinen Innenflächen-Schnitten sondiert.

Nach derzeitigem Kenntnisstand lassen sich zwei Bebauungsmuster erkennen. Bei zahlreichen Burgen scheint sich die Bebauung weitestgehend auf den direkten Hinterfrontbereich der Wallanlagen konzentriert zu haben, während die zentralen Bereiche der Burghöfe nur gering oder gar nicht bebaut wurden. Bislang zeigten sich jedenfalls bei allen Burgengrabungen verschiedene Baulichkeiten im direkten Wallhinterfrontbereich. Die Errichtung von Gebäuden in unmittelbarer Nähe des Walls hatte mehrere Vorteile. Einerseits waren die Häuser besser vor direktem Beschuss, ferner auch vor Wind und Wetter geschützt; andererseits ergab sich die Möglichkeit, die Hausbauten unter Ersparnis von Material- und Arbeitsaufwand in die Wallbauten zu integrieren. Die ausschließliche oder vornehmliche Bebauung des Hinterfrontbereichs ließ sich z. B. in Bosau-,,Bischofswarder“, auf dem „Wallberg" von Sirksfelde (Struve 1981, 21, 108) und auf dem Burgwall von Lebbin (Lubin) (Janowski 2011a, 473 ff.; 2011b, 20) feststellen. Neben mittelgroßen, rechteckigen oder annähernd quadratischen Häusern, wie sie u. a. in Groß Görnow, 


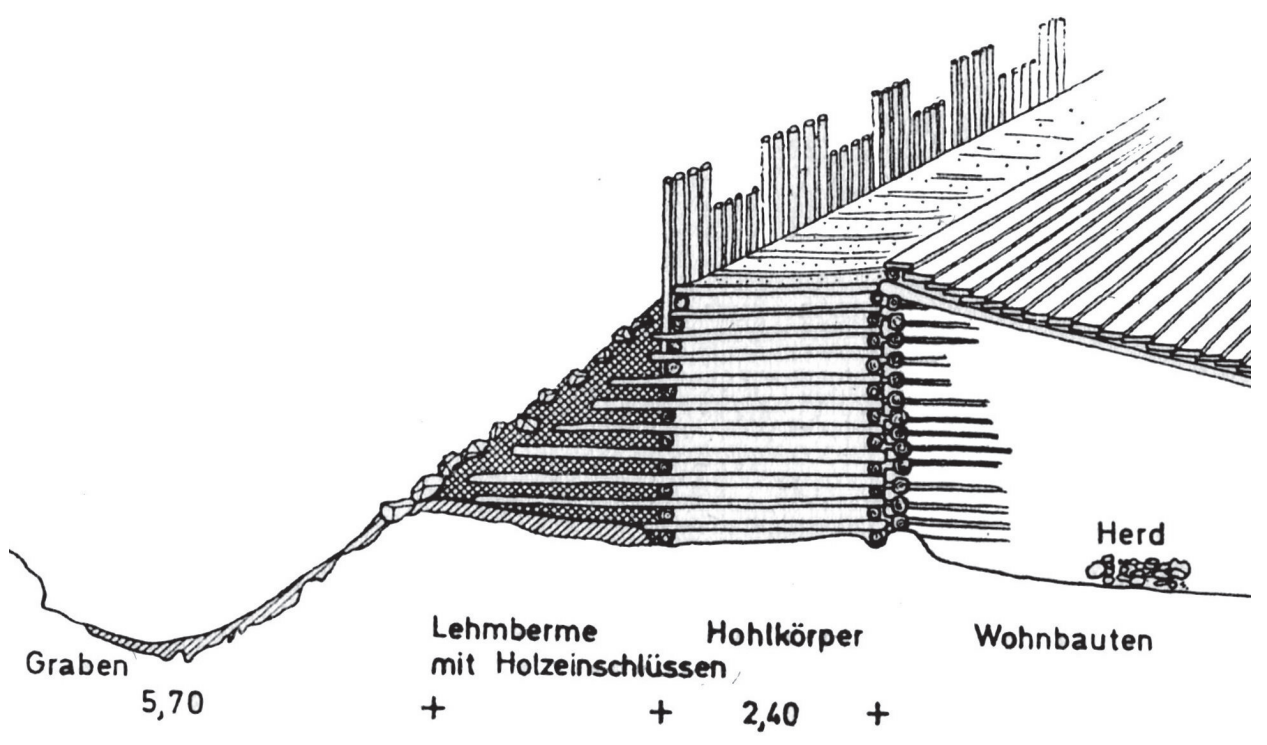

Abb. 12: Feldberg, Rekonstruktion der Befestigung mit Wehrmauer in Rostbauweise (Herrmann 1970, Abb. 10)

Wendorf (Schuldt 1985a, 319 ff., 330 f. Abb. 12 Abb. 24) oder auf der „Ravensburg“" (Schoknecht 1971, 263 Abb. 205) nachgewiesen werden konnten, wurden im Wallhinterfrontbereich häufiger Reihen länglich-schmaler Häuser errichtet, die sich in Form langer, flach-muldenförmiger Gruben abzeichnen. Derartige Befunde kennen wir u. a. von den Burgen in Groß Görnow (Schuldt 1985a, 318 ff. Abb. $10,11,14)$ und Sternberger Burg, vom Letzteren in Form eines etwa $75 \mathrm{~m}$ langen Grabens, der zunächst der Materialentnahme für den Befestigungsbau diente, später aber zur Errichtung zahlreicher jeweils $3 \mathrm{~m}$ breiter Langhäuser genutzt wurde (Schuldt 1983, 99 ff. bes. Abb. 10-16). Vergleichbar ist diesem Befund ein etwa $45 \mathrm{~m}$ langer Hausgraben mit mehreren Feuerstellen, der in der Vorburg des Potzlower Burgwalls entdeckt wurde (Biermann/Henning 2013, 34 Abb. 7) ${ }^{20}$. Reihen von dicht nebeneinander errichteten Häusern im Wallhinterfrontbereich sind auch für Gołańcz Pomorska und Kędrzyno belegt (Losiński 1972, 148 f.); auf Letzerem erweiterte sich die Bebauung in einer späteren Siedlungsphase auch auf den palisadenbefestigten Burghofrand im Süden und Westen (Losiński 1972, 148 f.). Das Gleiche gilt für den zweigliedrigen Burgwall von Lubiechowo, auf dem sich hinter dem äußeren Wall zwei Hausreihen mit insgesamt 30 bis 40 teils langen Gebäuden (3-4 × 3-8 m) abzeichneten (Łosiński 1972, 149). Eine Reihe länglicher Gruben

${ }^{20}$ Dieser stellt aber insofern eine Besonderheit dar, als dass dieser im Verlauf der Befestigung der Hauptburg auf deren Außenseite errichtet wurde. 

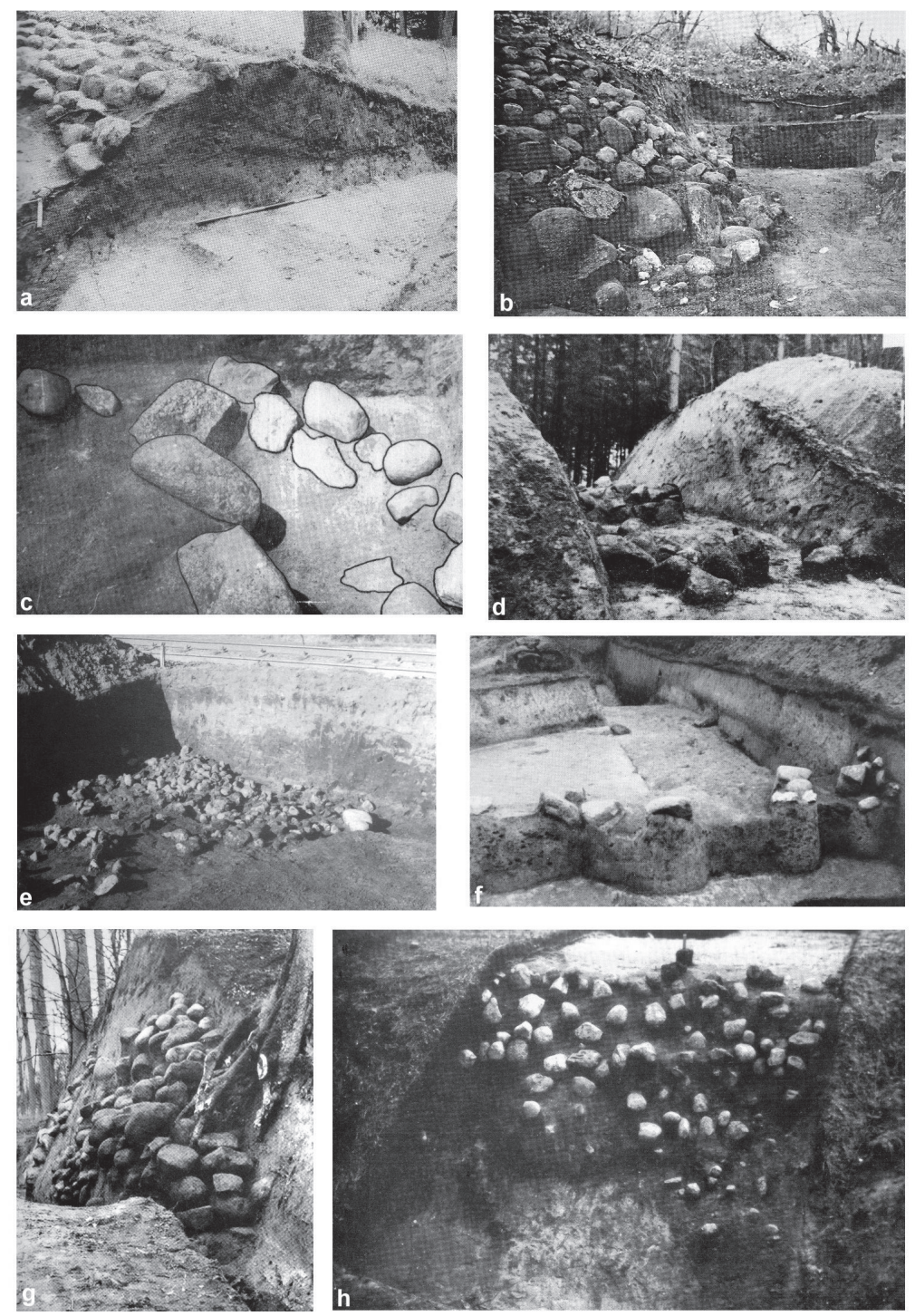

Abb. 13: Steinelemente beim Befestigungsbau. a: Feldberg, Böschungsbelag (Westwall, bei Schnitt II) (Herrmann 1970, Abb. 6). b: Groß Görnow, Steinbelag der westlichen Torwange (Schnitt III) (Schuldt 1985a, Abb. 7). c: Radacz, Steinreihe am Wallaußenfuß (Viertel 90) (Siuchniński 1962, Taf. 6). d: Sternberger Burg, Steinreihen auf der Wallaußenseite (Schnitt I) (Schuldt 1983, Abb. 3). e: Kretomino, dichtes Steinpflaster unter dem Wall (Schnitt I/77) (Skrzypek 2006, Taf IIB). f: Sukow, Steinreihen auf der Außenseite des Walls (Schnitt II) (Schuldt 1964, Abb. 144). g: Liepen, massive Steinfronten im Torbereich (Wallschnitt) (Schuldt 1962, Abb. 99). h: Radacz, Steinbelag der Wallvorderfront (Viertel 52/33) (Olczak 1961, Taf. 5) 


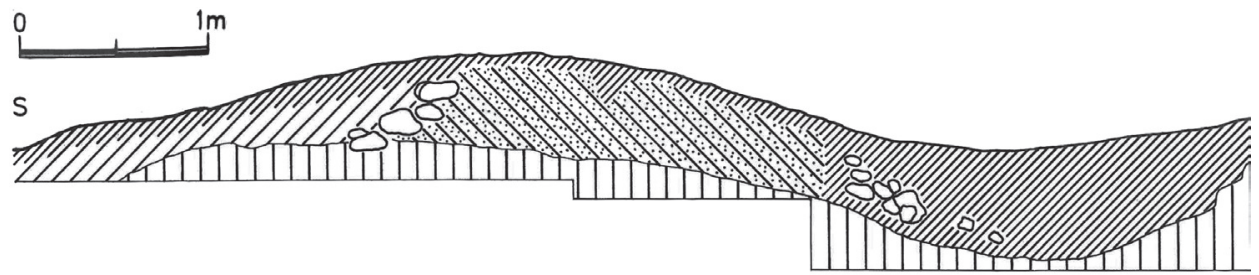

Abb. 14: Wangels-Grammdorf, „Farver Burg“ (Vorburgbefestigung), Erdwall mit Steinblenden und Rest einer Pfostenspur (Struve 1981, Abb. 41)

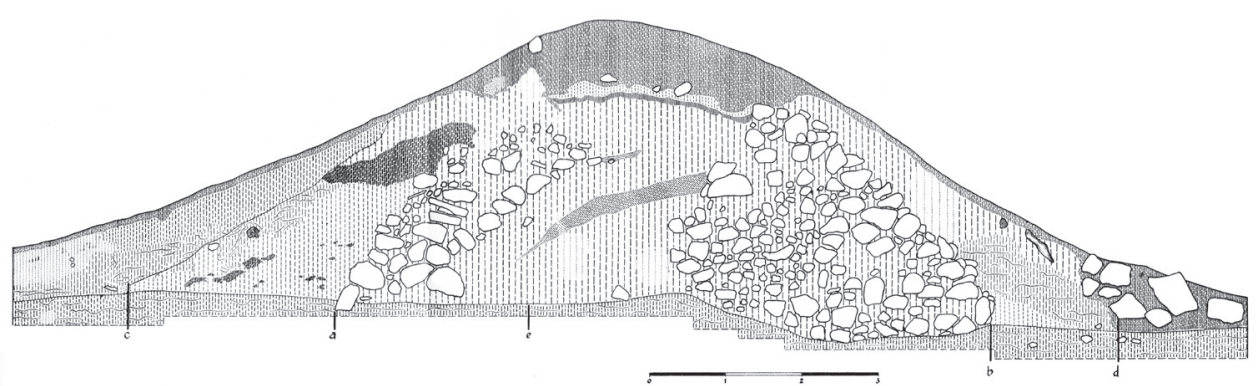

Abb. 15: Liepen, Erdwall mit massiven Steinlagen an Vorder- und Hinterfront (Schuldt 1962, Abb. 97)

zeigte sich ebenfalls im Hinterfrontbereich des Walls von Hohennauen ${ }^{21}$. In den meisten der genannten Befunde befanden sich Feuerstellen, womit diese als eingetiefte Bereiche beheizbarer und somit bewohnter Häuser zu interpretieren sind; davon zeugen außerdem der in diesen Gruben in teils großen Mengen gefundene Hausrat und Siedlungsabfall in Gestalt von Keramik, Tierknochen und verschiedenen Gebrauchsgegenständen (u. a. Wetzsteine, Knochenpfrieme und Spinnwirtel). Neben den Wohngebäuden, die die Burgbewohner beherbergten und teils vielleicht auch als Unterkünfte für Wachmannschaften dienten, dürften in unmittelbarer Wallnähe auch die Burgbrunnen angelegt worden sein, um raschen Zugang zu Löschwasser zu haben. Bester Beleg dafür sind zwei im unmittelbaren Rückfrontbereich des Burgwalls von Lenzen-,,Neuehaus“ entdeckte Brunnen, die etwa $30 \mathrm{~m}$ voneinander entfernt lagen und vielleicht zu einem den gesamten Burghof umgebenden ringartigen System von Brunnenanlagen gehörten (Biermann/Kieseler in Vorbereitung). Da Pfostenlöcher weitestgehend fehlen ${ }^{22}$, lassen sich die Gebäude

${ }^{21}$ H. Kennecke $(2016,208)$ interpretiert diese als reine Materialentnahmegruben.

${ }_{22}$ Einzelne Pfostenstellungen in unmittelbarer Nähe von Hausgruben, wie sie beispielsweise auf dem Burgwall von Gołańcz Pomorska angetroffen wurden, könnten als Stützen einer Dachkonstruktion gedient haben (Łosiński 1972, 141). 


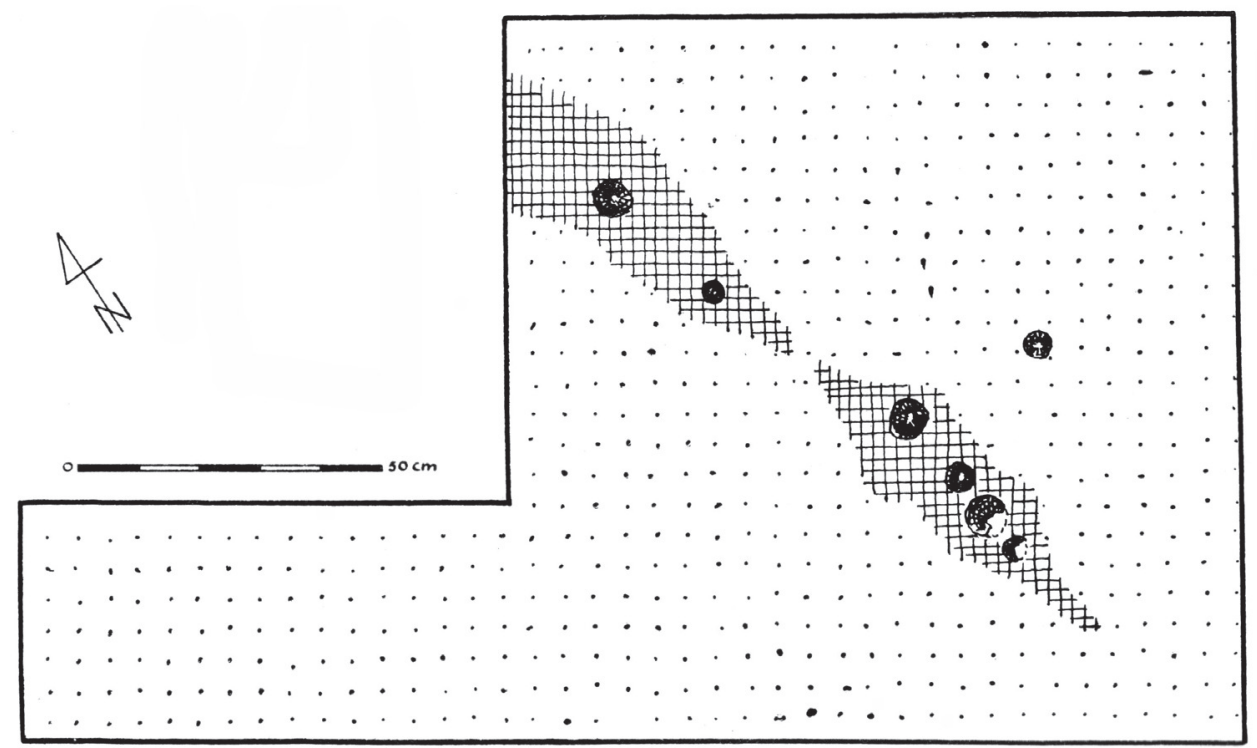

Abb. 16: Stare Drawsko, Pfostenspuren einer leichten Zaun- oder Palisadenbefestigung an der wallfreien Burghofkante über dem Steilhang (Planum) (Janocha 1964, Abb. 7)

grundsätzlich als leicht eingegrabene bzw. flach unterkellerte Blockbauten rekonstruieren. Neben frei stehenden Gebäuden, die im Hinterfrontbereich häufig parallel, mitunter aber auch quer ${ }^{23}$ zum Wall standen, wurden vielleicht auch traufständige Kasemattenbauten errichtet, was den Zerstörungshorizonten allerdings nicht sicher entnommen werden kann.

Bei einigen Burgen, z. B. in Groß Görnow und Sternberger Burg (Schuldt 1983; 1985), zeigten sich in mehreren Innenflächensondagen keinerlei Siedlungsreste, sodass deren zentrale Burgareale wohl weitestgehend unbebaut geblieben sein dürften. Dass man aufgrund dieser Ergebnisse aber nicht grundsätzlich auf einen Freiraum schließen kann, zeigen beispielsweise die Untersuchungen auf dem Burgwall von Basthorst/Weberin, wo mit einer einzigen kleinen Innenflächensondage eine etwa $25 \mathrm{~m}$ vom inneren Wallfuß entfernt gelegene Hausgrube entdeckt wurde (Schuldt 1985a, 325 f. Abb. 16, 17). Insbesondere dürften die großräumigen Freiareale für die Viehhaltung, aber auch zu wirtschaftlichen Zwecken (Vorratsgruben) genutzt worden sein. In Radacz fanden sich im zentralen Burgbereich mehrere Siedlungsgruben, darunter auch eine ca. $2 \times 2 \mathrm{~m}$ große, oberflächlich mit Steinen bekränz-

${ }^{23}$ Nicht in jedem Falle standen die Häuser mit ihrer Traufseite zum Wall. So ließen sich auf dem Burgwall von Lenzen-,Neuehaus“ im Süden der Burg zwei länglich-rechteckige Hausgrundrisse von jeweils über $4 \mathrm{~m}$ Länge nachweisen, die mit ihren Längsachsen quer zum Wallverlauf ausgerichtet waren (Biermann/Kieseler in Vorbereitung). 


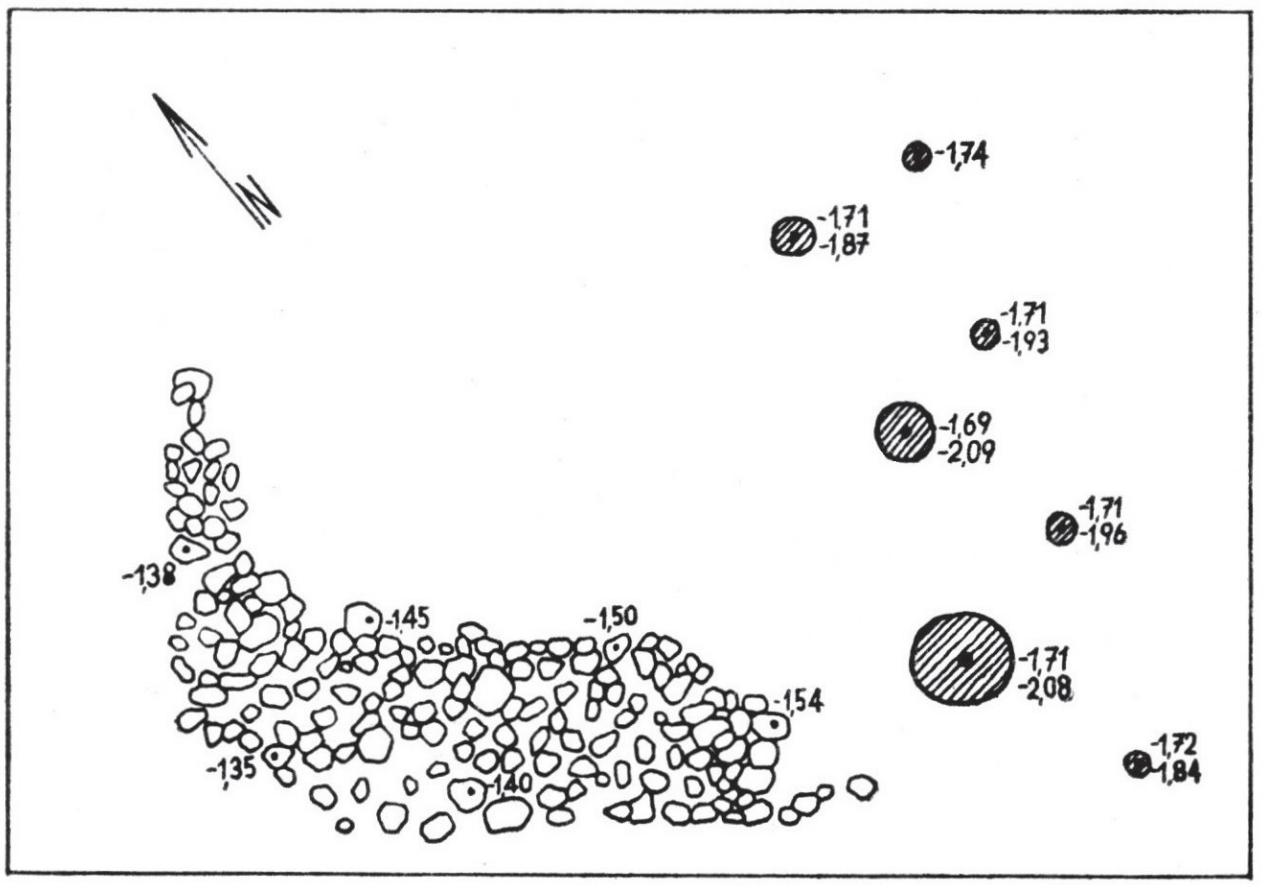

Abb. 17: Gołańcz Pomorska, Spuren eine Doppelpfostenreihe im Verlauf der wallfreien Burghofkante über dem angrenzenden Steilhang (Planum) (Łosiński 1972, Abb. 50)

te und mit brandigem Humus verfüllte Grube, die sicherlich mit einem feuerbasierten Produktionsprozess in Zusammenhang steht, zumal vom Fundplatz auch zahlreiche Eisenschlacken und einige Tondüsenfragmente vorliegen (Olczak 1961, 275 Taf. 3, 4).

Eine zweite Bebauungsform bildeten lange, mehr oder weniger geschlossene Hausreihen, die weite Teile des Burgareals einnehmen und nicht auf den Rückfrontbereich der Befestigungen begrenzt waren. Bei den Ausgrabungen in Feldberg ließen sich mehrere solcher Reihen rekonstruieren, die aus 4 bis $7 \mathrm{~m}$ breiten und 7 bis 13 langen, teils unterkellerten Häusern bestanden, die auf terrassierten Geländeabsätzen parallel zum Hang durch Ober- und Unterburg zogen (Herrmann 1970, 42 Abb. 13, 21; Slawen 1985, 167, 202 Abb. 71) (Abb. 19.c). Eine ähnliche Bebauungsstruktur scheint im Falle der zweiteiligen Burg von Zislow vorzuliegen, für die J. Herrmann (1970, Abb. 31, 32; Schoknecht 1991, 94) ebenfalls mehrere dem natürlichen Hangprofil folgende Hausreihen rekonstruierte (Abb. 19.a, b). Ein weiteres Beispiel ist der Burgwall von Bardy, wo in zwei langen Suchschnitten durch die Innenflächen von Haupt- und Vorburg Gebäudegrundrisse zutage traten, die zu mehreren, auf 4 bis $5 \mathrm{~m}$ breiten Terrassen auf dem Hangabfall angelegten Hausreihen gehört haben könnten (Losiński 1972, 149; vgl. 2001; 2008, 81 ff.) (Abb. 19.d, e). Andernorts ließ sich eine Reihenbebauung bislang nicht sicher nach- 


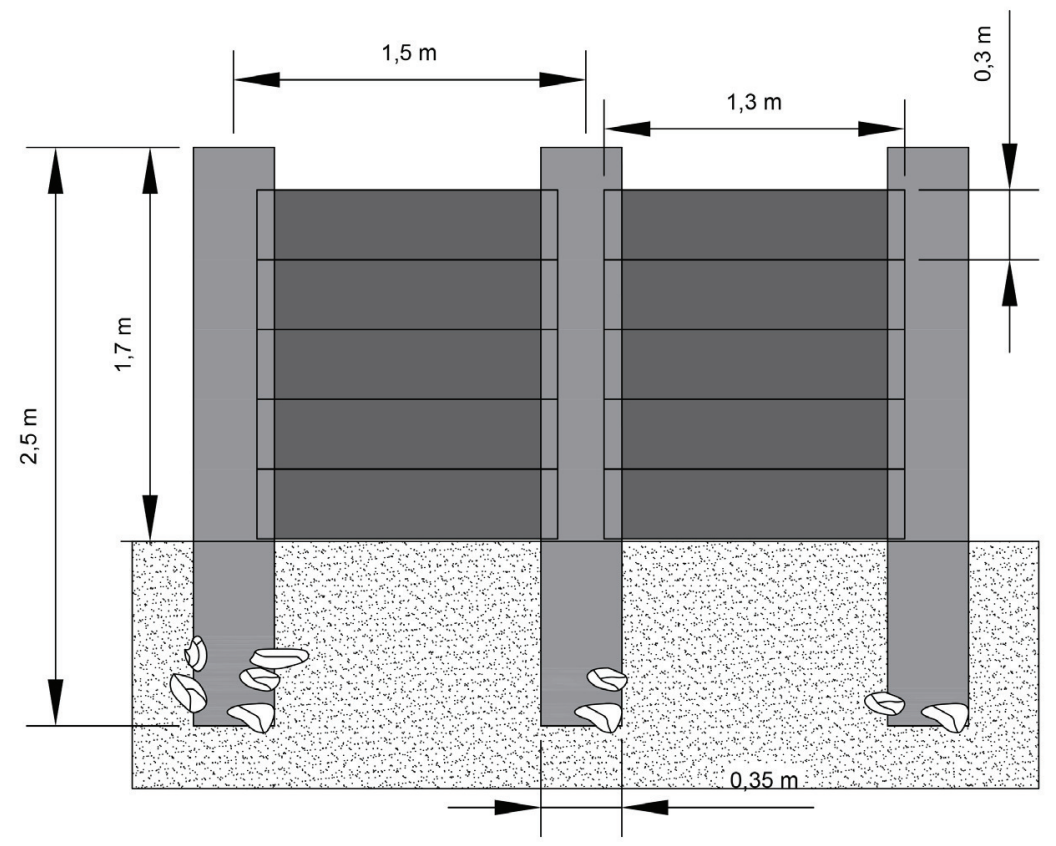

Abb. 18: Sternberger Burg, Rekonstruktion der Palisaden-Plankenwandbefestigung im Verlauf der beiden langen Steilhangseiten der Burg (Zeichnung A. Kieseler)

weisen, was v. a. auf die begrenzten Untersuchungen zurückzuführen ist. Die angeführten Beispiele weisen aber darauf hin, dass auch einige der frühen Großburgen eine vergleichsweise hohe Gebäudedichte mit regelmäßig erscheinender Bebauungsstruktur aufwiesen. Auf flächig, vielleicht in Reihen bebaute Burgareale deuten auch die Baubefunde vom "Schlossberg“ in Szczecin (Leciejewicz/ Łosiński 1983, 245 Abb. 209, 210), vom „Werderberg“ bei Potzlow (Biermann/ Henning 2013) und vom Burgwall in Glienke (Messal 2015, 48) hin.

\section{ZUSAMMENFASSUNG}

Geraume Zeit nach der slawischen Landnahme in den Gebieten an der südlichen Ostseeküste, die im Wesentlichen im letzten Drittel des 7. Jhs. erfolgte ${ }^{24}$ und zunächst nur einzelne Teilgebiete erfasste ${ }^{25}$, wurden dort die ersten Befestigungen

24 Biermann/Dalitz/Heußner 1999, 240; Brather 2001, 60 f.; Dulinicz 2006, 280; Ruchhöft 2008, 65; Łosiński 2008, 69 ff. Letzterer hält die Besiedlung u. a. des mittleren Parsęta-Gebiets (Mikroregion Białogard) auch schon am Ausgang des 6. Jhs.

${ }^{25}$ Zum Gebiet westlich der Oder siehe: Ruchhöft 2008, 65 ff. Abb. 27; zu Hinterpommern: Łosiński 1982, 45 ff. Abb. 7. 

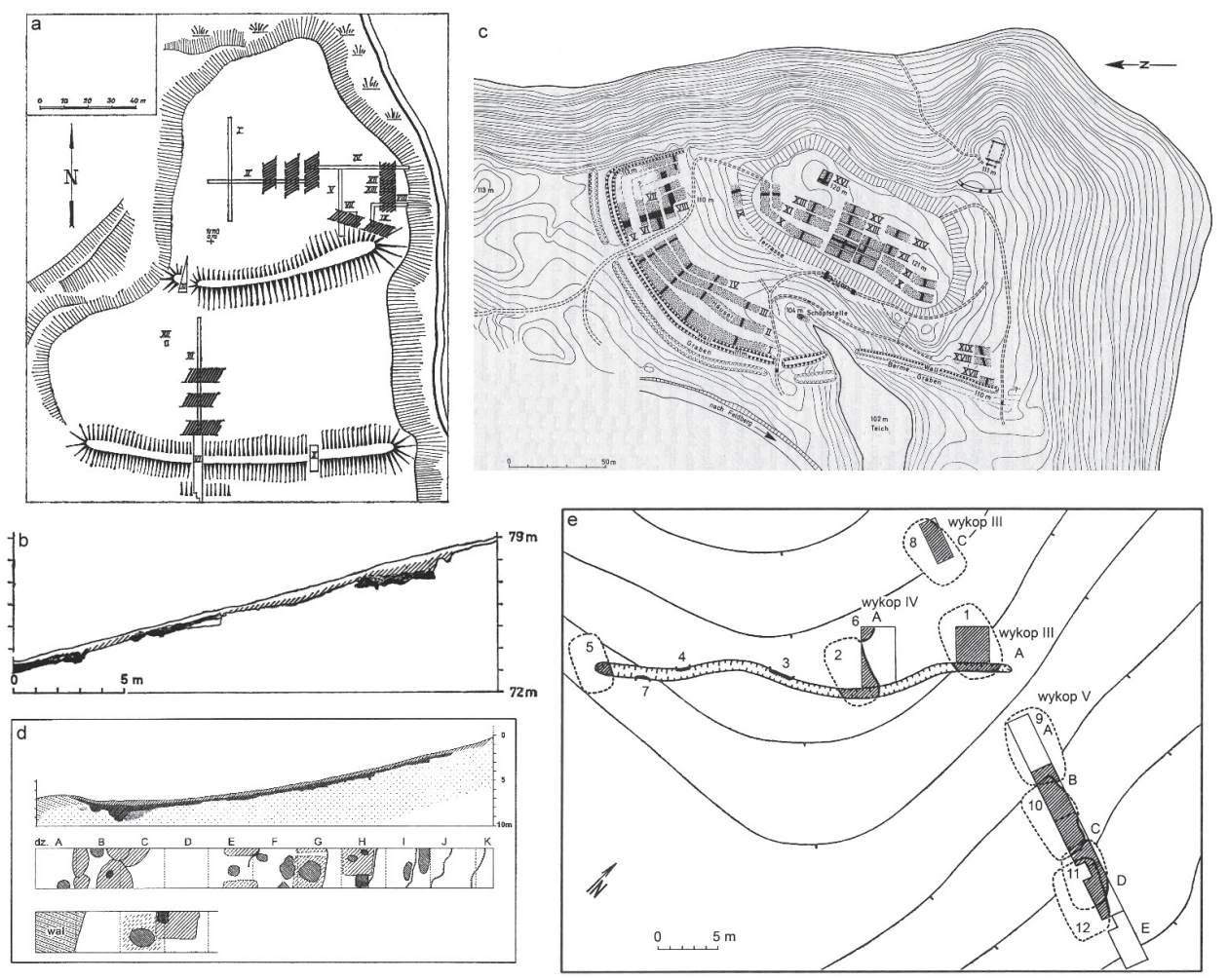

Abb. 19: Regelhafte Reihenbebauung großer Höhenburgen. a: Zislow, Schnittplan mit den Hausbefunden in Haupt- und Vorburg. b: Zislow, in den Steilhang eingetiefte Hausstellen in der Hauptburg (Schnitt II). c: Feldberg, auf Grundlage der Innenflächenbefunde rekonstruierte Reihen-Bebauung beider Burgareale. d: Bardy, in den Steilhang eingetiefte Haus- und Grubenbefunde in der kleinen Hauptburg. e: Bardy, regelmäßig angeordnete Hausbefunde in der großen Vorburg (Zusammenstellung A. Kieseler, leicht verändert nach Herrmann/Donat 1979a, Abb. 97, 98; Herrmann 1970, Abb. 21; Łosiński 2008, Abb. 2)

errichtet. Nach Ausweis der Dendrodaten (Sukow, Klempau, Wildberg [?]) entstanden die ältesten Anlagen bereits im Laufe des 8. Jhs. Die Masse der Burgen wurde jedoch erst um 800 (Friedrichsruhe) und besonders dann in der ersten Hälfte des 9. Jhs. errichtet (Abb. 1). In dem etwa $85.000 \mathrm{~km}^{2}$ großen Raum zwischen unterer Weichsel und Elbe, Ostseeküste und der Noteć-Warta-Spree-Havel-Linie wurden in einer 100- bis 150-jährigen Zeitspanne nach derzeitigem Kenntnisstand etwa 140 Burgen gebaut, die - neben etwa 40 oft noch viel größeren Burgen in Kleinpolen (Poleski 2011, 170 f., 178 Abb. 37) und einigen Anlagen in den polnischen-tschechischen Sudeten (Jaworski 2005, 94 f. Abb. 31 Tab. 2) - in ihrer Gesamtheit die älteste geschlossene Burgengroßlandschaft des westslawischen Gebiets nördlich der Mittelgebirge bildeten. Hingegen wurden im Binnenland, in ei- 


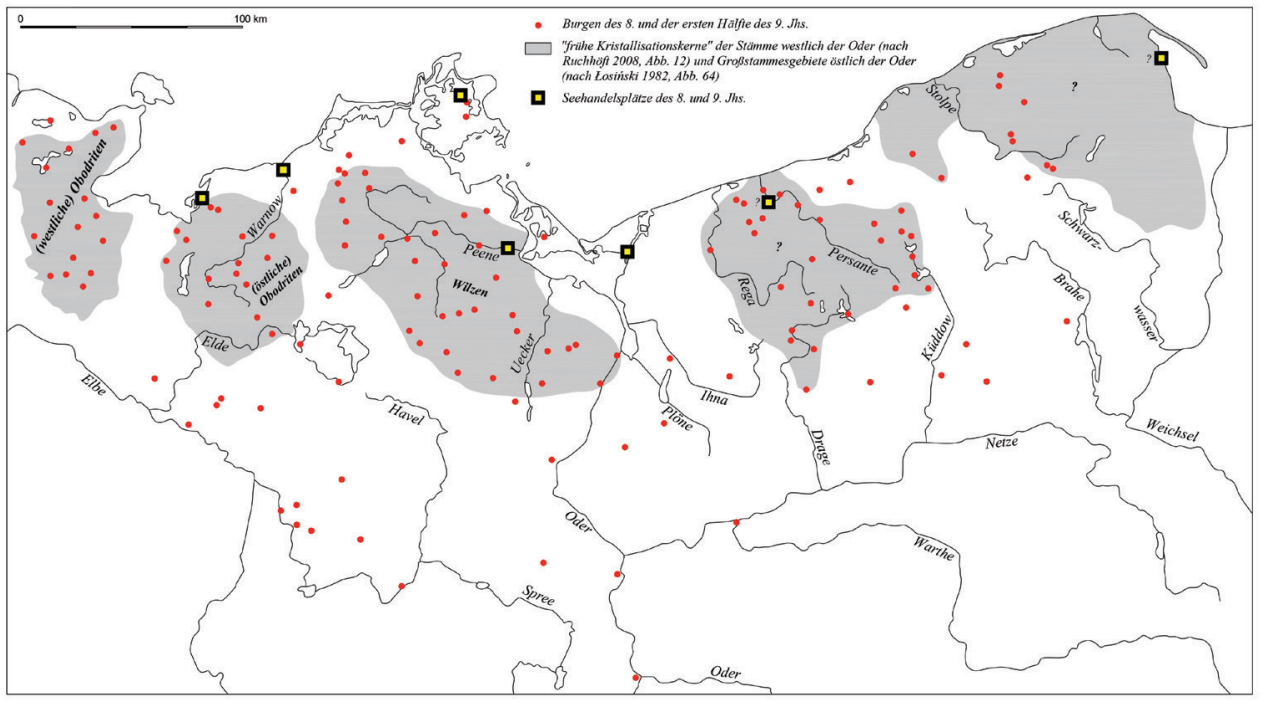

Abb. 20: Verbreitung der frühen slawischen Burgen an der südlichen Ostseeküste vor dem Hintergrund der frühen Großstammesgebiete und der Lage der Seehandelsplätze des 8. und 9. Jhs. (von West nach Ost: Groß Strömkendorf, Rostock-Dierkow, Ralswiek, Menzlin, Wolin, Bardy-Świelubie, Puck [Putzig]) (Zeichnung A. Kieseler)

nem breiten Streifen vom südlichen Brandenburg über Großpolen und das nördliche Niederschlesien bis nach Masowien und Podlasien, zunächst keine Burgen errichtet $^{26}$; in diesen von fremden Kultureinflüssen wohl weitestgehend abgeschotteten Regionen setzte der Burgenbau erst im mittleren oder späten 9. Jh. mit der Errichtung der kleinen Ringwälle (teils des „Tornower Typs“) ein ${ }^{27}$, die in weiten Teilen des nordwestslawischen Raums im späten 9. und 10. Jh. den dominierenden Burgentyp bildeten ${ }^{28}$.

Unter dem Gesichtspunkt der Wallbauweise geben sich die frühen Burgen an der südlichen Ostseeküste als eine sehr einheitliche Architekturform zu erkennen. Die von sehr breiten Wehrgräben begleiteten Wälle bestanden in erste Linie aus flach-breiten Erdschüttungen, die je nach verwendetem Schüttmaterial mehr oder weniger stark mit Holzkonstruktionen verstärkt wurden. Bei diesen handelte es sich um pfostengestützte und/oder durch im oberen Wallbereich eingezogene Ankerbalken miteinander verbundene Schalwände an den Außenfronten. Diese wurden ver-

${ }^{26}$ Ausnahmen bilden die wahrscheinlich schon im 7. Jh. errichteten burgbergartigen und nur schwach befestigten Anlagen von Haćki/Podlasien und Szeligi/Masowien mit Bezügen in den ostslawischen und baltischen Raum (Kobyliński/Szymański 2015, 123 ff.).

27 Biermann 2001, 630 f.; zu frühen Dendrodatierungen dieses Burgentyps siehe: Kieseler 2016, 304 [mit weiterer Literatur].

28 So auch an der südlichen Ostseeküste (z. B. Groß Raden, Teterow, Świelubie [Zwilipp], Wrześnica [Freetz]); für die westodrischen Gebiete siehe: Ruchhöft 2008, 50 ff. Abb. 17. 
mutlich vornehmlich aus zugearbeiteten Flachbohlen errichtet, wie die Holzbefunde aus Friedrichsruhe (Messal 2013, Abb. 2), Scharstorf (Struve 1981, Abb. 49, 50) oder Ralswiek nahelegen. In einigen Fällen lassen sich konstruktive Holzelemente in Form von längs zum Wall errichteten Zwischenwänden oder Kästen erkennen (u. a. Oldenburg, Mecklenburg, Scharstorf); in kleinerer Zahl wurden - abgesehen von hölzernen Oberbauten - auch reine Erdwälle errichtet, wenn festes Schüttmaterial keiner weiteren Sicherung bedurfte (Lehmwall von Lenzen-,Neuehaus“). Kastenartige Rostkonstruktionen wohl vornehmlich aus ganzen oder gespalteten Rundstämmen, wie sie dann bei den mittelslawischen Burgen dominieren ${ }^{29}$, kommen vergleichsweise selten vor (Bergen auf Rügen, Feldberg, Kretomino). Die „Holzarmut“ bei den frühen Burgen im Norden des westslawischen Raums wurde schon von den Altmeistern der mecklenburgisch-pommerschen Burgenforschung - E. Schuldt $(1988,92)$ und W. Łosiński $(1973,176)$ - konstatiert. Die für den wilzischen Raum von J. Herrmann (1967, 207 ff.) herausgestellte Feldsteinbauweise sollte nicht überbewertet werden (vgl. Brather 1998, 121 f.; Biermann 2011, 155 f.); es steht aber fest, dass für die Errichtung zahlreicher Burgen Feldsteine in größeren Mengen als konstruktive (Liepen, Sukow, Radacz, Wangels-Grammdorf) und nicht-konstruktive Elemente (Feldberg) Verwendung fanden.

In Bezug auf Lage, Anlageform und Größe weisen die Burgen nur wenige Gemeinsamkeiten auf. Höhenburgen treten ebenso auf wie Niederungsanlagen, in Abhängigkeit von den topographischen Verhältnissen (Brather 1998, 116 Abb. 1). Ebenso gibt es eine Vielzahl verschiedener Grundrisse (Abb. 2-6), wobei natürlich insbesondere die Höhenburgen in Anlehnung an das Terrain häufiger eine amorphe Gestalt erhielten, die Niederungsburgen hingegen in regelmäßiger Form - zumeist rundlich oder länglich-oval, selten auch viereckig (Glienke) - errichtet werden konnten. Auch in Hinblick auf die Größe bilden die Burgen ein weites Spektrum, dass von sehr kleinen Befestigungen von unter 0,1 ha Innenfläche bis zu extrem großen Anlagen von über 4 ha Innenfläche reicht (Abb. 2-6). Dabei ist v. a. auf den großen Unterschied zwischen den sehr großen Burgen im Mecklenburg sowie Vorpommern und den nahezu ausschließlich sehr kleinen Anlagen in Hinterpommern und Pommerellen zu verweisen (vgl. Brather 1998, 117 Abb. 2) (Abb. 7). Trotz dieses breiten Spektrums sind letztlich nahezu alle Burgen als Großburgen zu bezeichnen, zumindest im direkten Vergleich mit den Ringwällen der mittelslawischen Zeit, die zwischen 20 und maximal $50 \mathrm{~m}$ Innendurchmesser aufweisen. Als ein besonderes Merkmal der frühen Anlagen lassen sich jedoch die Abschnittswälle ansprechen; diese treten zwar in weiten Teilen des westslawischen Raums

${ }^{29}$ Im Arbeitsgebiet z. B. die Burgen von Świelubie (Łosiński 1972, 182 Abb. 82), Wrześnica (Niesyty/Hoppel 1998, 167 f. Abb. 2), Kołobrzeg-Budzistowo (Leciejewicz 2007, 35 ff. Abb. 17-27) und Groß Raden (Schuldt 1985b, 70 f. Abb. 75, 76). 
auch noch in mittel- und spätslawischer Zeit auf ${ }^{30}$, doch nicht mehr in dieser Häufigkeit. Die nicht mit Wehrmauern befestigten Burghofkanten, die zumeist im Bereich steiler, z. T. an Seen oder Flusstäler angrenzende Steilhänge verliefen, wurden dabei mit leichteren, teils auf bzw. in Flachwällen oder Erdanschüttungen errichteten Holzkonstruktionen gesichert; bei diesen handelte es sich wohl vorwiegend um Palisaden oder Pfosten-Plankenwand-Konstruktionen, die im Wesentlichen der Bauweise der gängigen Wallschalwände entsprachen.

Im Allgemeinen geben sich die frühen Burgen an der südlichen Ostseeküste sowohl in Bezug auf die Anlageformen als auch auf die Wehrkonstruktionen als wehr- und bautechnisch anspruchsvolle, hoch entwickelte Bauten zu erkennen. Die breiten Wälle, teils mit Steinlagen verstärkt und zumeist mit breiten Wehrgräben versehen, bildeten massive Befestigungslinien, die in einigen Fällen durch Vorwälle verstärkt wurden (z. B. Tutow, Feldberg); insbesondere einige der geschickt an die Geländesituation angepassten Höhenburgen bildeten schwer einzunehmende Bollwerke (vgl. hierzu v. a. Bastian 1957). Auch die Schalwandkonstruktionen mit ihren Pfostensicherungen sowie den Ösen-, Haken- und Lochverbindungen lassen auf hohe handwerkliche Fertigkeiten der Burgenbauer schließen. In diesem Sinne ist W. Łosiński $(1973,176)$ nicht zuzustimmen, wenn er in Bezug auf die Wandlungen im Burgenbau von mittelslawischen Anlagen spricht, deren Wälle „technisch reifer und vollkommener waren" als jene der Frühzeit. Gerade die kleinen Ringwälle des 9. und 10. Jhs. wurden in denkbar einfacher Weise mit kastenartigen Rostkonstruktionen errichtet, deren Hauptbestandteile unbearbeitete, an beiden Enden gekehlte Rundstämme bildeten; und auch in Bezug auf die Anlageform dürften die zumeist im sumpfigen Niederungsgelände über rundlichem Grundriss errichteten Burgen mit flachen Sohlgräben kaum wehrhafter gewesen sein; das heißt allerdings nicht, dass diese vor dem Hintergrund der damaligen Kriegstechnik leichter zu bezwingen waren. Vielleicht geht dieser Wandel mit allgemeinen krisenhaften Entwicklungen in mittelslawischer Zeit einher, was v. a. durch das Ende der hochwertigen Keramik des Typs Feldberg-Kędrzyno angezeigt wird.

Die frühe Errichtung der Burgen an der südlichen Ostseeküste lässt sich mit mehreren Faktoren erklären. Denkbar ist, dass der slawische Burgenbau insbesondere in den westlich der Oder gelegenen Gebieten als Reaktion auf die kriegerischen Auseinandersetzungen zwischen Franken und Slawen einsetzte und somit Ausdruck ,akuter äußerer Bedrohung“" war ${ }^{31}$; dies betraf offenbar auch die Gebiete fernab der fränkisch-slawischen Grenze, wie der in den fränkischen Reichsan-

30 Beispielsweise die mittelslawischen Burgen von Chobienia (Köben) und Popęszyce (Poppschütz) in Schlesien (Kieseler 2012; Biermann/Kieseler/Nowakowski 2016) oder mehrere spätslawische Anlagen an der unteren Weichsel (Janowski 2004, 110).

31 Brather 1996, 210; 2006, 49 [Zitat]; vgl. Henning 2002, 144; Messal 2013, 99. Auch der frühe Burgenbau in Südpolen könnte mit einer äußeren Bedrohung in direktem Zusammenhang stehen, zunächst durch das Awaren-Khaganat, späterhin durch das Großmährische Reich (Poleski 2011, 173, 178); ähnlich zu den ältesten böhmischen Burgen: Profantová 2016, 236. 
nalen belegte Feldzug Karls des Großen zum Sitz des slawischen rex Dragowit im Jahre 789 belegt, der mit einiger Wahrscheinlichkeit im wilzischen Kernraum an der Peene $\operatorname{lag}^{32}$. Unabhängig davon stand die Errichtung von Burgen mit einem gesellschaftlichen Differenzierungsprozess in Zusammenhang. Ausdruck einer im Laufe des 8. Jhs. entstehenden Oberschicht sind zunächst die Burgen selbst, die die größten Bauprojekte des frühmittelalterlichen Ostmitteleuropas darstellen. Es ist m. E. nur schwer vorstellbar, dass die teils gewaltigen Anlagen in einer Art Gemeinschaftsarbeit als „Volksburgen“ errichtet wurden; vielmehr lässt der arbeitsintensive, in mehreren Etappen erfolgende Bauprozess, für den ein Teil der Bevölkerung aus dem eigentlichen Produktionsprozess für einige Zeit abgestellt werden musste, eine koordinierende Instanz erkennen, die in der Siedlungsgemeinschaft zunächst vielleicht nur als eine Art primus inter pares agierte, später jedoch zum Herrschaftsträger avancierte ${ }^{33}$. Auch die mehrgliedrige Anlageform zahlreicher Burgen, also die Unterteilung in eine fast immer kleinere Haupt- oder Oberburg und eine oder mehrere Vor-/Unterburgen (u. a. Neubrandenburg-,,Ravensburg“", Friedrichsruhe, Drense, Bardy, Lubiechowo), dürfte nicht nur ein mehrstufiges Verteidigungssystem darstellen, sondern mit einer ganz bewusst angestrebten räumlichen Trennung unterschiedlicher Gesellschaftsgruppen in Zusammenhang stehen; außerdem werden hier unterschiedliche Funktionsbereiche erkennbar, denn die groBen Flächen der Vorburgen dienten im Gefahrenfall zur Aufnahme der umliegenden Bevölkerung. Darüber hinaus künden zahlreiche elitäre Kleinfunde (Sporen, Waffen, Trachtbestandteile) und in ihrer Architektur oder Lage von den gängigen Burghofbauten abweichende Bauwerke (Oldenburg, Feldberg [?]) von der Anwesenheit der Stammeseliten auf den Burgen ${ }^{34}$. Darüber hinaus bildeten einige der hier genannten Burgen über mehrere Jahrhunderte bestehende „Fürstenburgen“ (Oldenburg, Mecklenburg, Friedrichsruhe, Drense, Szczecin), deren Keime sicher schon in frühslawischer Zeit zu suchen sind (Ruchhöft 2008, 42 ff.).

Der frühe Burgenbau und die dahinter stehende soziale Differenzierung der Slawen an der südlichen Ostseeküste lassen sich auf die rasche ökonomische Entfaltung in diesen Territorien zurückführen, die sicher mit den ab dem frühen 8 . Jh. an der Küste errichteten Seehandelsplätzen in Zusammenhang steht (siehe hierzu Biermann 2014, 161 ff.). Die skandinavisch geprägten Siedlungen, in denen Handwerker und Kaufleute aus verschiedenen Gebieten spezialisiertem Handwerk nachgingen und Handel trieben, dürften in regem Güteraustausch mit den Siedlern des Hinterlands gestanden haben, wobei das Handelsgut der Slawen sicher vornehmlich

${ }^{32}$ Zur Problematik der Lokalisierung der civitas Dragaviti an der Peene, für die u. a. der Burgwall von Vorwerk bei Demmin (Herrmann 1969) oder der Siedlungskomplex von Menzlin-Görke (Dulinicz 2006, 245) vorgeschlagen wurden, siehe zuletzt ausführlich: Ruchhöft 2008, 97 f.; zu einer Lokalisierung im Havelgebiet zuletzt zusammenfassend: Kennecke 2016, $217 \mathrm{f}$.

${ }^{33}$ Vgl. Sikora 2014, 138; Kieseler 2016, 306.

${ }^{34}$ Biermann 2011, 161; kritisch zur Identifizierung von Eliten auf Grundlage besonderen Fundguts zuletzt: Ruchhöft/Schirren 2013, 218. 
landwirtschaftliche Produkte, daneben aber auch Sklaven bildeten (Biermann 2011, 166; 2014, 164). Den frühen Ballungsräumen slawischer Besiedlung lassen sich jeweils ein oder zwei Seehandelsplätze zuordnen (Abb. 20): Im Gebiet der westlichen Obodriten bildete Oldenburg einen bedeutenden, küstennahen, überregional eingebundenen Marktort; den östlichen Obodriten lassen sich Reric (Groß Strömkendorf) und sicher auch jener von Rostock-Dierkow zuordnen ${ }^{35}$, der über die Warnow mit dem Kerngebiet in direkter Verbindung stand. Für den wilzischen Kernraum in Ostmecklenburg, Vorpommern und der Uckermark spielte zweifelsohne der Seehandelsplatz bei Menzlin eine herausragende Rolle, der aus allen Regionen des Hinterlands über Peene, Tollense, Trebel und Uecker problemlos zu Wasser zu erreichen war. Auch dem burgenreichen Besiedlungsschwerpunkt im mittleren Hinterpommern lässt sich wahrscheinlich ein bedeutender Seehandelsplatz zuweisen; dieser wurde bislang zwar noch nicht lokalisiert, doch sprechen das skandinavisch geprägte Hügelgräberfeld an der unteren Parsęta für einen sich dort befindlichen Seehandelsplatz, der nach F. Biermann $(2006,21)$ flussabwärts des großen Burgwalls von Bardy, vielleicht in Kołobrzeg-Budzistowo selbst zu suchen ist. Auf das westliche Hinterpommen und Pommerellen lässt sich dieses Bild nicht übertragen. Zwar gab es mit Wolin auch an der Odermündung einen bedeutenden Seehandelsplatz, doch entwickelte sich dieser erst im Laufe des 9. Jhs. zu einem überregional bedeutenden Umschlagplatz und erreichte - spätestens ab der zweiten Hälfte des 9. Jhs. mit einem Holz-Erde-Wall befestigt (Cnotliwy 2014, 267 f.) seine Blütezeit erst im 10. Jh. ${ }^{36}$, zu einer Zeit also, in der die meisten anderen Siedlungen bereits wieder untergegangen waren. Auch in dem von W. Łosiński (1982, Abb. 64) rekonstruierten Großstammesgebiet in Pommerellen lassen sich nur wenige Burgen dem frühen Horizont zuweisen, und ob in Puck (Putzig) ein früher Seehandelsplatz bestand, ist ungewiss.

Die „Kristallisationsräume“ der nordwestslawischen Großstämme decken sich im Großen und Ganzen mit den Verbreitungsräumen der frühen Burgen (Abb. 20), die als Sitze von Herrschaftsträgern in den weit in das Binnenland hineinreichenden Einzugsgebieten des Regionalhandels mit den Seehandelsplätzen entstanden. Die großflächigen Burgen waren dabei aber nicht nur Aufenthaltsorte der Oberschichten, die im Kampf mit den Nachbarstämmen um natürliche Ressourcen zur Errichtung von Burgen gezwungen waren; sie dienten zugleich der Aufnahme der Bevölkerung aus den umliegenden Siedlungen, ohne welche die Verteidigung der teils mehrere hundert Meter langen Befestigungslinien nicht möglich war (vgl. Biermann 2011, 159).

Ungeklärt bliebt bislang die Frage, weshalb die Burgen östlich der Oder - von wenigen Ausnahmen abgesehen (Trzynik [?], Stare Drawsko, Bardy) - sehr viel kleiner sind (zumeist unter 0,5 ha Innenfläche) als jene westlich des Stroms (vgl.

${ }^{35}$ Rostock-Dierkow wurde von J. Herrmann $(2006,165)$ den wilzischen Stämmen zugeordnet.

${ }^{36}$ Filipowiak 2000, 152 ff.; Filipowiak/Gundlach 1992, 47; Brather 2001, 146 f. 
Brather 1998, Abb. 2) (Abb. 7). Da sich die (in beiden Landstrichen ähnlichen) topographischen Verhältnisse kaum als Ursache für diese deutliche Diskrepanz benennen lassen, sind andere Hintergründe zu suchen (vgl. Brather 1996, 189; 1998, 117). Geht man davon aus, dass sich auch in der Größe einer Burg die Stammesmacht widerspiegelt, dann ließen sich die kleineren Burgen Hinterpommerns mit einer bescheideneren demographischen Entwicklung und einer begrenzten Wirtschaftskraft in Verbindung bringen, wofür vielleicht auch die geringe Zahl der Seehandelsplätze in diesem Raum sprechen könnte. Gegebenenfalls ist die geringere Größe der östlichen Burgen auch Ausdruck einer im Vergleich zu den abodritischen und wilzischen Stämmen abweichend verlaufenden Gesellschaftsentwicklung der hinterpommerschen Stämme, bei denen der refugiale Aspekt der Burgen keine größere Rolle spielte. Letztlich wäre aber auch denkbar, dass sich hinter den kleinen Burgen schlichtweg ein chronologischer Faktor verbirgt: Für die westlichen Territorien deutet sich an, dass die kleineren Anlagen mehrheitlich in die Spätphase des frühen Burgenhorizonts datieren, so beispielsweise die Burgwälle von Kieve, Menkendorf, Scharstorf und Lenzersilge; die kleineren, häufig rundlich-ovalen, vollständig umwallten und in der Niederung gelegenen Burgen markieren dabei vielleicht einen Übergangshorizont von den älteren Großburgen zu den kleinen Ringwällen, die ab der zweiten Hälfte des 9. Jhs. entstehen (Biermann 2011, 157). Diese Thesen zu den Burgen Hinterpommerns lassen sich jedoch aufgrund des derzeitigen Forschungsstands nicht untermauern. Von besonderem Interesse sind diesbezüglich die künftig zu erwartenden Ergebnisse eines aktuellen Forschungsprojekts zu den Burgen an der Rega in Hinterpommern, die die frühe Datierung einiger Anlagen bestätigen ${ }^{37}$.

\section{LITERATUR}

Bastian W. 1955 (1957), Mittelslawische Höhenburgen mit Hang- und Böschungslagen. „Bodendenkmalpflege in Mecklenburg" nie ma numeracji, to tom 1955, wydany w $1957 \mathrm{r}$.

Berlekamp H. 1965, Die Schwedenschanze von Camitz, Kr. Ribnitz-Damgarten. Arbeitsmaterialien des Bezirksfachausschusses für Ur- und Frühgeschichte 2, 33-36.

Biermann F. 2001, Zwischen Polen, Russen und Balten: Die frühmittelalterliche Burg von Sypniewo in Masowien. „Archäologisches Korrespondenzblatt“ 31/4, 617-635.

- 2006, Frühstadt und Burg an der südlichen Ostseeküste vom 8. bis zum 12. Jh. In: F. Biermann, M. Müller, C. Herrmann (Hrsg.), Castella Maris Baltici VII. Beiträge der Tagung „Die Stadt als Burg. Architektur-, rechts- und sozialhistorische Aspekte befestigter Städte im Ostseeraum vom Mittelalter bis zur frühen Neuzeit. 03.-06. September 2003 in Greifswald (Greifswald), 15-24.

- 2011, Functions of the Large Feldberg Type Strongholds from the $8^{\text {th }} / 9^{\text {th }}$ Century in Mecklenburg and Pomerania. „Sprawozdania Archeologiczne” 63, 149-173.

- 2014, Zentralisierungsprozesse bei den nördlichen Elbslawen. In: P. Sikora (Hrsg.), Zentralisierungsprozesse und Herrschaftsbildung im frühmittelalterlichen Ostmitteleuropa. Studien zur Archäologie Europas 23 (Bonn), 157-194.

${ }^{37}$ Freundliche Mitteilung von Prof. Dr. M. Rębkowski (Szczecin). Die Burgenuntersuchungen sind Teil des Projekts „Polska i Pomorze w kształtowaniu cywilizacji europejskiej (od słowiańskich plemion do przełomu XII/XIII w.)“. 
- 2015, Wehrelemente slawischer Burgen im frühen und hohen Mittelalter. In: J. Zeune (Hrsg.), „Dem Feind zu Trutz": Wehrelemente an mittelalterlichen Burgen. Kolloquium des Wissenschaftlichen Beirats der Deutschen Burgenvereinigung (Goslar), 38-50.

Biermann F., Dalitz S., Heußner K.-U. 1999, Der Brunnen von Schmerzke. Stadt Brandenburg a. d. Havel, und die absolute Chronologie der frühslawischen Besiedlung im nordostdeutschen Raum. „Prähistorische Zeitschrift“" 74/2, 219-243.

Biermann F., Gossler N., Kennecke H. 2009, Archäologische Forschungen zu den slawenzeitlichen Burgen und Siedlungen in der nordwestlichen Prignitz. In: J. Müller, K. Neitmann, F. Schopper (Hrsg.), Wie die Mark entstand. 850 Jahre Mark Brandenburg. Forschungen zur Archäologie im Land Brandenburg 11 (Wünsdorf), 36-47.

Biermann F., Henning J. 2013, Orientalisches Silber in der Uckermark - der frühmittelalterliche Burgwall auf dem Werderberg bei Potzlow. „Heimatkalender Prenzlau“ 56, 32-41.

Biermann F., Kieseler A., Nowakowski D. 2016, Köben an der Oder (Chobienia) - Forschungen zum Wandel der Siedlungs- und Herrschaftsverhältnisse im mittelalterlichen Niederschlesien. In: Biermann F., Kieseler A., Nowakowski D., Burg, Herrschaft und Siedlung im mittelalterlichen Niederschlesien. Die slawischen Ringwälle von Köben (Chobienia) und Kleinitz (Klenica) im Kontext der Frühgeschichte des mittleren Oderraums. Studien zur Archäologie Europas 27 (Bonn), 23-210.

Biermann F., Kieseler A. (in Vorbereitung), Die Burgwälle von Lenzen-Neuehaus und Lenzersilge. Archäologische Forschungen zum frühgeschichtlich-mittelalterlichen Befestigungswesen in der Nordwestprignitz.

Brather S. 1996, Feldberger Keramik und frühe Slawen. Studien zur nordwestslawischen Keramik der Karolingerzeit. Universitätsforschungen zur prähistorischen Archäologie 34 (Bonn).

- 1998, Karolingerzeitlicher Befestigungsbau im wilzisch-abodritischen Raum. Die sogenannten Feldberger Höhenburgen. In: J. Henning, A.T. Ruttkay, Frühmittelalterlicher Burgenbau in Mittel- und Osteuropa. Tagung Nitra 1996 (Bonn), 115-126.

- 2001, Archäologie der westlichen Slawen. Siedlung, Wirtschaft und Gesellschaft im früh- und hochmittelalterlichen Ostmitteleuropa (Berlin - New York).

- 2006, Zwischen „Fluchtburg” und „Herrensitz”. Sozialgeschichtliche Interpretationen früh- und hochmittelalterlicher Burgwälle in Ostmitteleuropa. „Archaeologia Baltica” 6, 40-57.

Cnotliwy E. 1982, Biatogard. Gród wczesnopolski. Biblioteka Popularnonaukowa 4 (Koszalin).

- 1983, Umocnienia obronne. In: E. Cnotliwy, L. Leciejewicz, W. Łosiński (red.), Szczecin we wczesnym średniowieczu. Wzgórze zamkowe. Polskie Badania Archeologiczne 23 (Wrocław - Warszawa - Kraków - Gdańsk - Łódź), 253-254.

- 2005, Pierwsze dendrodaty z białogardzkiego grodziska. „Folia Praehistorica Posnaniensia” 13/14, 271-278.

- 2014, Umocnienia obronne wczesnośredniowiecznego Wolina. In: B. Stanisławski, W. Filipowiak (red.), Wolin wczesnośredniowieczny. Część 2. Origines Polonorum VII (Warszawa), 197-277.

Donat P. 1984, Die Mecklenburg - eine Hauptburg der Obodriten. Schriften zur Ur- und Frühgeschichte 37 (Berlin)

Dulinicz M. 2006, Frühe Slawen im Gebiet zwischen unterer Weichsel und Elbe. Eine archäologische Studie. Studien zur Siedlungsgeschichte und Archäologie der Ostseegebiete 7 (Neumünster).

Filipowiak W. 2000, Wollin - ein frühmittelalterliches Zentrum an der Ostsee. In: A. Wieczorek, H.-M. Hinz (Hrsg.), Europas Mitte um 1000. Beiträge zur Geschichte, Kunst und Archäologie. Band 1 (Stuttgart), 152-162.

Filipowiak W., Gundlach H. 1992, Wolin. Vineta. Die tatsächliche Legende vom Untergang und Aufstieg der Stadt (Rostock).

Grebe K. 1970, Die altslawische Vorburgsiedlung von Wildberg, Kr. Neuruppin. „Ausgrabungen und Funde" $15,150-156$

Henning J. 2002, Der slawische Siedlungsraum und die ottonische Expansion östlich der Elbe. In: J. Henning (Hrsg.), Europa im 10. Jahrhundert. Archäologie einer Aufbruchszeit (Mainz), 131-146.

Herrmann J. 1967, Gemeinsamkeiten und Unterschiede im Burgenbau der slawischen Stämme westlich der Oder. „Zeitschrift für Archäologie“ 1, 206-258. 
- 1968, Siedlung, Wirtschaft und gesellschaftliche Verhältnisse der slawischen Stämme zwischen Oder/ Neiße und Elbe. Studien auf der Grundlage archäologischen Materials. Schriften der Sektion für Vor- und Frühgeschichte 23 (Berlin).

Herrmann J. 1969, Die Schanze von Vorwerk bei Demmin - Die Civitas des wilzischen Oberkönigs Dragowit? „Ausgrabungen und Funde“ 14/4, 191-197.

- 1970, Feldberg, Rethra und das Problem der wilzischen Höhenburgen. „Slavia Antiqua“ 16, 33-69.

- 1998, Ralswiek auf Rügen. Die slawisch-wikingischen Siedlungen und deren Hinterland. Teil II Kultplatz, Boot 4, Hof, Propstei, Mühlenberg, Schlossberg und Rugard. Beiträge zur Ur- und Frühgeschichte Mecklenburg-Vorpommerns 33 (Lübstorf).

- 2006, Ralswiek auf Rügen. Die slawisch-wikingischen Siedlungen und deren Hinterland. Teil IVDer Silberschatz vor 850. Naturwissenschaftliche Untersuchungen. Versuch einer Bilanz. Beiträge zur Ur- und Frühgeschichte Mecklenburg-Vorpommerns (Schwerin).

Herrmann J., Donat P. (Hrsg.) 1973, Corpus archäologischer Quellen zur Frühgeschichte auf dem Gebiet der Deutschen Demokratischen Republik (7. bis 12. Jahrhundert). 1. Lieferung (Berlin).

- 1979a, Corpus archäologischer Quellen zur Frühgeschichte auf dem Gebiet der Deutschen Demokratischen Republik (7. bis 12. Jahrhundert). 2. Lieferung (Berlin).

- 1979b, Corpus archäologischer Quellen zur Frühgeschichte auf dem Gebiet der Deutschen Demokratischen Republik (7. bis 12. Jahrhundert). 3. Lieferung (Berlin).

Herrmann J., Heußner K.-U. 1991, Dendrochronologie, Archäologie und Frühgeschichte vom 6. bis 12. Jh. in den Gebieten zwischen Saale, Elbe und Oder. „Ausgrabungen und Funde” 36, 255-290.

Janocha H. 1964, Archeologiczne badania sondażowo-weryfikacyjne na wczesnośredniowiecznych obiektach obronnych w Starym Drawsku, stanowisko 2 i Kluczewie, pow. Szczecinek w 1964 r. „Materiały Zachodniopomorskie" 10, 1964, 183-202.

Janowski A. 2004, Grody nadwiślańskie na Pomorzu Wschodnim we wczesnym średniowieczu. Tom 1. Unveröffentlichte Dissertation an der Nikolaus-Kopernikus-Universität Toruń (Toruń).

- 2011a, Grodzisko wczesnośredniowieczne w Lubinie koło Gryfic. Wyniki badań w 2007 roku. In: M. Fudziński, H. Paner (red.), XVII Sesja Pomorzoznawcza. Tom 1 (Gdańsk 2011), 471-477.

- 2011b, Wyniki najnowszych badań na grodziskach wczesnośredniowiecznych w Lubinie koło Gryfic i Dobrej koło Nowogardu. In: J. Kochanowska (red.), Trzebiatów - spotkania pomorskie 2010 (Trzebiatów), 17-26.

Jaworski K. 2005, Grody w Sudetach (VIII-X w.) (Wrocław).

Kempke T. 2001, Slawische Keramik. In: H. Lüdtke, K. Schietzel (Hrsg.), Handbuch zur mittelalterlichen Keramik in Nordeuropa. Band 1 (Neumünster), 209 -256.

Kennecke H. 2016, Burg und Siedlung von Hohennauen (Havelland) in früh- und mittelslawischer Zeit. In: F. Biermann, T. Kersting, A. Klammt (Hrsg.), Die frühen Slawen - von der Expansion bis zu gentes und nationes. Beiträge der Sektion zur slawischen Frühgeschichte des 8. Deutschen Archäologiekongresses in Berlin, 06.-10. Oktober 2014. Band 1. Beiträge zur Ur- und Frühgeschichte Mitteleuropas 81/1 (Langenweißbach), 203-221.

Kieseler A. 2012, Der slawische Burgwall von Poppschütz (Popęszyce, pow. nowosolski) - eine frühe Burgwallgrabung in der Provinz Niederschlesien. In: F. Biermann, T. Kersting, A. Klammt, T. Westphalen (Hrsg.), Transformationen und Umbrüche des 12./13. Jahrhunderts. Beiträge der Sektion zur slawischen Frühgeschichte der 19. Jahrestagung des Mittel- und Ostdeutschen Verbandes für Altertumsforschung in Görlitz, 01.-03. März 2010. Beiträge zur Ur- und Frühgeschichte Mitteleuropas 64 (Langenweißbach), 229-261.

Kieseler A. 2016, Der slawische Burgwall von Kleinitz (Klenica) im nördlichen Niederschlesien. In: F. Biermann, A. Kieseler, D. Nowakowski, Burg, Herrschaft und Siedlung im mittelalterlichen Niederschlesien. Die slawischen Ringwälle von Köben (Chobienia) und Kleinitz (Klenica) im Kontext der Frühgeschichte des mittleren Oderraums. Studien zur Archäologie Europas 27 (Bonn), 211-465.

Kobyliński Z., Szymański W. 2015, Grodzisko w Haćkach na Podlasiu. In: M. Żurek, M. Krasna-Korycińska (red.), Grody średniowiecznego Mazowsza. Archaeologica Hereditas 4 (Warszawa - Zielona Góra), 111-145.

Krug V. 1971, Geomagnetische Vermessung der Burgwallanlage Liepen. Arbeitsmaterialien des Bezirksfachausschusses für Ur- und Frühgeschichte 5, 37-41. 
Leciejewicz L. 2007, Grodzisko w Budzistowie. Badania w latach 1954-1958. In: L. Leciejewicz, M. Rębkowski (red.), Kołobrzeg. Wczesne miasto nad Battykiem. Origines Polonorum II (Warszawa), 31-110.

Leciejewicz L., Łosiński W. 1983, Rozwój osady i jej zabudowy. In: E. Cnotliwy, L. Leciejewicz, W. Łosiński (red.), Szczecin we wczesnym średniowieczu. Wzgórze Zamkowe. Polskie Badania Archeologiczne 23 (Wrocław - Warszawa - Kraków - Gdańsk - Łódź ), 245-252.

Łosiński W. 1972, Początki wczesnośredniowiecznego osadnictwa grodowego w dorzeczu dolnej Parsęty (VII-X/XI w.) (Wrocław - Warszawa - Kraków - Gdańsk).

- 1973, Probleme der archäologischen Forschungen zum frühen Mittelalter in Westpommern. „Przegląd Archeologiczny" 21, 165-199.

- 1982, Osadnictwo plemienne Pomorza (VI-X wiek) (Wrocław - Warszawa - Kraków - Gdańsk Łódź).

- 2001, O zabudowie niektórych grodów wielecko-zachodniopomorskich typu Feldberg/Kędrzyno. In: E. Wilgocki (red.), Instantia est Mater Doctrinae. Księga Jubileuszowa Prof. dr. hab. Władysława Filipowiaka (Szczecin), 125-134.

- 2008, Pomorze Zachodnie we wczesnym średniowieczu. Studia archeologiczne. Collectio Archaeologica Historica et Ethnologica III (Poznań).

Łosiński W., Olczak J., Siuchniński K. 1971, Źródła archeologiczne do studiów nad wczesnośredniowiecznym osadnictwem grodowym na terenie województwa koszalińskiego. Tom IV (Poznań).

Messal S. 2013, Friedrichsruhe. Eine slawische Burg im südwestlichen Mecklenburg.

- Besiedlungsgeschichte - Befestigungsbau - Herrschaftsbildung. In: K. H. Willroth, H.-J. Beug, F. Lüth, F. Schopper (Hrsg.), Slawen an der unteren Mittelelbe. Untersuchungen zur ländlichen Besiedlung, zum Burgenbau, zu Besiedlungsstrukturen und zum Landschaftswandel. Frühmittelalterliche Archäologie zwischen Ostsee und Mittelmeer 4 (Wiesbaden), 91-102.

- 2015, Glienke. Eine slawische Burg des 9. und 10. Jahrhunderts im östlichen Mecklenburg. Frühmittelalterliche Archäologie zwischen Ostsee und Mittelmeer 5 (Wiesbaden 2015).

Niesyty M., Hoppel P. 1998, Konstrukcje obronne wczesnośredniowiecznego grodziska we Wrześnicy, stan. 7, gm. Stawno, woj, stupskie. Acta Archaeologica Pomoranica I, 167-174.

Olczak J. 1961, Badania archeologiczne na wczesnośredniowiecznym grodzisku w Radaczu, pow. Szczecinek. „Materiały Zachodnio-Pomorskie” 7, 371-380.

Olczak K., Siuchniński K. 1966, Źródła archeologiczne do studiów nad wczesnośredniowiecznym osadnictwem grodowym na terenie województwa koszalińskiego. Tom I (Poznań).

- 1968, Źródla archeologiczne do studiów nad wczesnośredniowiecznym osadnictwem grodowym na terenie województwa koszalińskiego. Tom II (Poznań).

- 1970, Źródla archeologiczne do studiów nad wczesnośredniowiecznym osadnictwem grodowym na terenie województwa koszalińskiego. Tom III (Poznań).

- 1985, Źródta archeologiczne do studiów nad wczesnośredniowiecznym osadnictwem grodowym na terenie województwa stupskiego. Tom I (Poznań).

- 1989, Źródla archeologiczne do studiów nad wczesnośredniowiecznym osadnictwem grodowym na terenie województwa stupskiego. Tom II (Poznań).

Poleski J. 2011, Naszacowice. Ein frühmittelalterlicher Burgwall am Dunajec. Band II. Fundstoff, Funktion, interregionale Beziehungen, Burgenbau in Kleinpolen. Moravia Magna. Seria Polona III (Kraków).

Profantová N. 2016, Errichtung und Zerstörung der ersten frühmittelalterlichen Burgwälle in Böhmen (8./9. Jahrhundert). In: F. Biermann, T. Kersting, A. Klammt (Hrsg.), Die frühen Slawen - von der Expansion bis zu gentes und nationes. Beiträge der Sektion zur slawischen Frühgeschichte des 8. Deutschen Archäologiekongresses in Berlin, 06.-10. Oktober 2014. Band 1. Beiträge zur Ur- und Frühgeschichte Mitteleuropas 81/1 (Langenweißbach), 223-239.

Ruchhöft F. 2008, Vom slawischen Stammesgebiet zur deutschen Vogtei. Die Entwicklung der Territorien in Ostholstein, Lauenburg, Mecklenburg und Vorpommern im Mittelalter. Archäologie und Geschichte im Ostseeraum 4 (Rahden/Westf.).

Ruchhöft F., Schirren C. M. 2013, Spuren von Eliten? Zur systematischen Funderfassung am Beispiel frühgeschichtlicher Burgwälle des südlichen Peeneraums. In: F. Biermann, T. Kersting, A. Klammt 
(Hrsg.), Soziale Gruppen und Gesellschaftsstrukturen im westslawischen Raum. Beiträge der Sektion zur slawischen Frühgeschichte der 20. Jahrestagung des Mittel- und Ostdeutschen Verbandes für Altertumsforschung in Brandenburg (Havel), 16. bis 18. April 2012. Beiträge zur Ur- und Frühgeschichte Mitteleuropas 70 (Langenweißbach), 211-219.

Schoknecht U. 1970 (1971), Probleme der Ravensburg bei Neubrandenburg. „Bodendenkmalpflege in Mecklenburg“ ..., 263-272, nie ma numeracji, tom 1970, wydany w 1971 r. (brak tomu).

1974, Wallprofile der Ravensburg bei Neubrandenburg. „Bodendenkmalpflege in. Mecklenburg“..., 239-245, nie ma numeracji, tom 1973, wydany w 1974 r.

Schoknecht U. 1991, Der altslawische Burgwall von Zislow, Kreis Röbel. In: U. Schoknecht (Bearb.), Zislow - Ergebnisse archäologischer Untersuchungen. Beiträge zur Ur- und Frühgeschichte Mecklenburg-Vorpommerns 25 (Schwerin), 93-95.

Schuldt E. 1960 (1962), Der slawische Burgwall von Liepen, Kr. Rostock, und die Burgen im Stammesgebiet der Circipaner. „Bodendenkmalpflege in Mecklenburg“..., 201-214, nie ma numeracji, tom 1960, wydany w $1962 \mathrm{r}$.

- 1963 (1964), Die Ausgrabungen im Gebiet der "Alten Burg“ von Sukow, Kreis Teterow. „Bodendenkmalpflege Mecklenburg“..., 217-262, nie ma numeracji, tom 1963, wydany w 1964 r.

- 1967, Die slawischen Burgen von Neu-Nieköhr/Walkendorf, Kreis Teterow. Beiträge zur Ur- und Frühgeschichte der Bezirke Rostock, Schwerin und Neubrandenburg 1 (Schwerin).

- 1982 (1983), Die frühslawische Befestigung von Sternberger Burg, Kreis Sternberg. „Bodendenkmalpflege in Mecklenburg-Vorpommern“..., 97-145, nie ma numeracji, tom 1982, wydany w $1983 \mathrm{r}$.

- 1984 (1985a), Der Burgwall von Groß Görnow und die frühen slawischen Befestigungen im Gebiet der oberen Warnow. „Bodendenkmalpflege in Mecklenburg“..., 311-336, nie ma numeracji, tom 1984, wydany w $1985 \mathrm{r}$.

- 1985b, Groß Raden. Ein slawischer Tempelort des 9./10. Jahrhunderts in Mecklenburg. Schriften zur Ur- und Frühgeschichte 39 (Berlin).

- 1988, Der Holzbau bei den nordwestslawischen Stämmen vom 8. bis 12. Jahrhundert. Beiträge zur Ur- und Frühgeschichte der Bezirke Rostock, Schwerin und Neubrandenburg 21 (Berlin).

Sikora P. 2014, Die Anfänge der Zentralisierungsprozesse im frühen Mittelalter in Polen. In: P. Sikora (Hrsg.), Zentralisierungsprozesse und Herrschaftsbildung im frühmittelalterlichen Ostmitteleuropa. Studien zur Archäologie Europas 23 (Bonn) 127-151.

Siuchniński K. 1962, Sprawozdanie z badań wykopaliskowych na wczesnośredniowiecznym grodzisku w Radaczu, pow. Szczecinek w 1962 r. „Materiały Zachodnio-Pomorskie” 8, 9-27.

- 1964, Sprawozdania z badań wykopaliskowych przeprowadzonych w okolicy Radacza, pow. Szczeci$n e k, w 1963 r$. „Materiały Zachodniopomorskie” 10, 153-182.

Skrzypek I. 2006, Wczesnośredniowieczne grodzisko w Kretominie pod Koszalinem. Komunikat o rezultatach archeologicznych w latach 1977-1979. In: M. Dworaczyk, A. B. Kowalska, S. Moździoch, M. Rębkowski (red.), Świat Stowian wczesnego średniowiecza (Szczecin - Wrocław), 55-74.

Herrmann J. (Bearb.) 1985, Die Slawen in Deutschland. Geschichte und Kultur der slawischen Stämme westlich von Oder und Neiße vom 6. bis 12. Jahrhundert. Ein Handbuch (Berlin).

Stark J. 2003, Der frühslawische Bohlenweg im Klempauer Moor, Hansestadt Lübeck, und der Burgwall von Klempau, Kreis Herzogtum Lauenburg. Mitteilungen der Deutschen Gesellschaft für Archäologie des Mittelalters und der Neuzeit 14, 85-91.

Struve K.W. 1981, Die Burgen in Schleswig-Holstein. Band 1. Die slawischen Burgen (Neumünster).

Szafrański W. 1957, Badania na grodzisku w Swobnicy, pow. Gryfino. „Materiały Zachodnio-Pomorskie” 3, $25-74$.

- 1960, Swobnica (Wildenbruch). Ein Burgwall der Lausitzer Kultur in Westpommern. In: Frühe polnische Burgen. Berichte über archäologische Ausgrabungen (Weimar), 39-46.

Toločko P.P. 1991, Der Burgwall Starigard/Oldenburg und das slawische Befestigungswesen. In: M. Müller-Wille (Hrsg.), Starigard/Oldenburg. Ein slawischer Herrschersitz des frühen Mittelalters in Ostholstein (Neumünster), 103-122.

Wesołowski S. 1983, Wykop XI. In: E. Cnotliwy, L. Leciejewicz, W. Łosiński (red.), Szczecin we wczesnym średniowieczu. Wzgórze Zamkowe. Polskie Badania Archeologiczne 23 (Wrocław - Warszawa - Kraków - Gdańsk - Łódź), 200. 